\title{
Ambient Technology to Assist Elderly People in Indoor Risks
}

\author{
Rami Yared * and Bessam Abdulrazak \\ Department of Computer Science, Université de Sherbrooke, Sherbrooke, QC J1K 2R1, Canada; \\ bessam.abdulrazak@usherbrooke.ca \\ * Correspondence: rami.yared@usherbrooke.ca; Tel.: +1-819-821-8000
}

Academic Editor: Subhas Chandra Mukhopadhyay

Received: 10 August 2016; Accepted: 26 September 2016; Published: 10 October 2016

\begin{abstract}
While elderly people perform their daily indoor activities, they are subjected to several risks. To improve the quality of life of elderly people and promote healthy aging and independent living, elderly people need to be provided with an assistive technology platform to rely on during their activities. We reviewed the literature and identified the major indoor risks addressed by assistive technology that elderly people face during their indoor activities. In this paper, we identify these risks as: fall, wrong self-medication management, fire, burns, intoxication by gas/smoke, and the risk of inactivity. In addition, we discuss the existing assistive technology systems and classify the risk detection algorithms, techniques and the basic system principles and interventions to enhance safety of elderly people.
\end{abstract}

Keywords: risk; indoor; assistive technology; elderly people; fall; self-medication management; fire; burn; intoxication; inactivity

\section{Introduction}

Aging can be defined as a time-dependent decline of the physiological functions of cells, tissues and organs [1]. Elderly people suffer from several factors that make them vulnerable. The major reason for the frailness of elderly people is aging. Aging causes a decline or degradation in several physiological functionalities of the human body, which makes elderly people vulnerable to different risks while performing indoor and outdoor activities of daily life. For example, visual impairment causes an elderly person to fall, which results in damage or harm and, in some situations, death. Fire and burning at home because of the inability to hear the fire alarm is another example of the vulnerability of elderly people due to the degradation of physiological capabilities when aging. Memory impairment is a huge obstacle preventing elderly people from performing or completing a task. A lot of daily routine tasks are consequences of simple tasks and people with memory impairment can easily forget the next task if they are distracted or interrupted, such as forgetting the next step in cooking a meal, forgetting to turn off the oven, etc. [2].

Also, several social factors play an important role in the vulnerability of elderly people, such as living alone, depression, and taking psychoactive medications. As an example, an elderly person may become at a high risk of poisoning because of eating poor quality food or misusing medications. Eating poor quality food or forgetting to take medications may be due to loneliness and the undesirability to cook healthy food or take a prescribed medication.

So, elderly people face a variety of risks while performing Activities of Daily Living (ADL), due to physical, sensorial and cognitive decline. This situation requires a great deal of attention because the number of elderly people is increasing constantly all over the world. The numbers are particularly critical in developed countries, since the advance in healthcare systems has enabled longer life. In Canada, the proportion of elderly people aged 65 years or over will represent between 
$23 \%$ and $25 \%$ of the population by 2036 , and between $24 \%$ and $28 \%$ by 2061 [3,4]. In Japan, the population of 65 -year-olds was about $25.1 \%$ of the total population in 2013 , and will be $40 \%$ in 2050 , which is the highest ratio of an aging population in the world [5]. In the United States, the number of elderly people is also on the rise: in 2010, there were 40.3 million people aged 65 and above, comprising $13 \%$ of the overall population. This proportion is 12 times higher than it was in 1900, when this group constituted only $4.1 \%$ of the population. By 2050, projections indicate that the population over 65 will comprise $20.9 \%$ of the population in the United States [6]. In Europe, by 2025 more than $20 \%$ of the population will be 65 or over, with a particularly rapid increase in the number of elderly people over 80 years old. In the United States, $40 \%$ of women and $19 \%$ of men aged 65 years and older live alone and do not have anyone in the home to assist with activities of daily living, provide care when they are sick, or assist them with home maintenance [7]. Therefore, researchers are paying special attention to the conditions of elderly people including work on: understanding the population, their needs, challenges faced, and risks in ADL. Improving the quality of life of elderly people is a very essential issue, particularly in developed societies. The most important step toward improving the life quality of elderly people is to assist in protecting them against risks they face while going about their daily life activities.

The interventions to reduce the consequences of risks affecting elderly people can be classified in two categories: human and technological interventions. The human intervention includes health and social assistance, provided by caregivers or relatives accompanying elderly people. This approach may have negative impacts on elderly people including emotional impact (e.g., it reduces the privacy of elderly people) and economic impact (e.g., it is often associated with a cost to the person, the family or the health system). On the other hand, the recent advances in Information and Communication Technology (ICT) (e.g., m-health, pervasive technologies (based on context awareness, Internet of Things, cloud computing, and sensor networks)) enabled the creation of new categories of solutions that may assist elderly people in ADL.

In this paper, we identify the major indoor risks addressed by assistive technology that elderly people face during their indoor activities: falls, wrong medication management, fire, burns, intoxication by gas/smoke, and inactivity. In addition, we review the existing ambient assistive technology systems to help elderly people against these risks. We also classify the risk detection algorithms and techniques and the basic system principles and interventions. To the best of our knowledge, this is the first research work that addresses indoor risks for elderly people and the related assistive technology.

The paper is organized as follows. After this introduction, Section 2 introduces the methodology followed in our research. Section 3 describes the major risks addressed by assistive technology that elderly people face during their indoor activities. Section 3 also presents the assistive technology systems that help elderly people in indoor risk situations. In this section, we mainly focus on reviewing the assistive technology systems and classify the risk detection algorithms and techniques and the basic system principles and interventions. Finally, Section 4 concludes the paper and discusses the ongoing and future directions.

\section{Methodology}

Our goal is to provide a review on the major indoor risks affecting elderly people that are addressed by assistive technology to help them, rather than a systematic review. We present in this section the methodology we used to identify the major risks and to review the existing research on assistive technology for these risks. Our methodology is based on a literature review identified through a search on the following databases: PubMed, ScienceDirect, IEEE Xplore and Google Scholar. These are the main databases that catalogue the research on risks faced by elderly people in indoor ADL and the related assistive technology. The choice of these databases is motivated by the fact that PubMed is specialized in human/medical factors, and the IEEE Xplore, Google Scholar, and ScienceDirect databases are more technology related. 
Based on reading of the abstracts retrieved from databases, we identified articles that describe risks and hazards that affect elderly people during indoor ADL. We also identified potential assistive technology that may support elderly people in these risk situations.

We disregarded in our study the articles that discuss research related to elderly people in other contexts (e.g., studies on chronic diseases, disabilities or other minor risks with no existing related assistive technology). We identified how major risks affect elderly people in their indoor ADL, and also extracted devices, systems or applications that may assist elderly people facing such risks, and identified the main addressed risks by assistive technology. We then iteratively clustered the risks and the assistive technology until we arrived at the categorization described in this paper.

\subsection{Search Items}

The following keywords were used: ("elderly" or "older" or "aged" or "aging" or "senior" or "elders") and ("assistive technology" or "information and communication technology") and "indoor" and ("risk" or "hazard") in the publication's titles, keywords, abstracts or full texts.

\subsection{Inclusion/Exclusion Criteria}

We include studies if they meet the following criteria: (1) involve elderly people; (2) include assistive technologies related to risks affecting elderly people during indoor ADL; (3) tackle tangible projects on assistive technology for indoor risks; and (4) state clearly the architecture and the fundamental principles of the assistive technology. We exclude assistive technology for mobility-impaired elderly people (e.g., assistive robots for monitoring and helping elderly people), and assistive technology related to health conditions. Studies in languages other than English, conceptual papers, opinions and unpublished full-text papers were excluded.

\subsection{Data Extraction and Analysis}

We reviewed the abstracts of the retrieved sources and filtered out irrelevant papers. In total, 3649 titles and abstracts were screened to find the qualified papers. Based on the predefined inclusion/exclusion criteria, we extracted 340 relevant papers that we insightfully analyzed. Based on the results of our analysis and the literature review study, we identified the major indoor risks addressed by assistive technology that elderly people face during their indoor ADL as follows: fall, wrong self-medication management, fire, burns, intoxication by gas/smoke and inactivity. The number of reviewed/selected papers for each identified risk is illustrated in Table 1.

Table 1. Identification of major indoor risks addressed by assistive technology.

\begin{tabular}{ccc}
\hline Indoor Risk & \# Reviewed Papers & \# Selected Relevant Papers \\
\hline Falls & 2630 & 200 \\
\hline $\begin{array}{c}\text { Wrong self-medication management } \\
\text { (non-adherence, abuse and misuse) }\end{array}$ & 123 & 73 \\
\hline Fire, burns and intoxication by gas/smoke & 84 & 32 \\
\hline Inactivity & 812 & 35 \\
\hline
\end{tabular}

\section{Major Indoor Risks Affecting Elderly People and the Assistive Technology}

\subsection{Fall Risk}

Falls are caused by a sudden loss of balance due to loss of stability or an unexpected slip during movement [8]. Falls are the major cause of fatal and non-fatal injuries among elderly people, which creates an obstacle for independent living [9]. According to the World Health Organization (WHO) [10], the frequency of falls increases with age and frailty. Therefore, elderly people are more 
concerned with fall risk due to their physical and functional decline. Elderly people living in nursing homes fall more often than those living in communities (30\% to 50\%) and $40 \%$ of them experience recurrent falls, because most elderly people living in nursing homes are frailer and these facilities accurately report accidents [11].

The Centers for Disease Control and Prevention in the USA reveal that each year, millions of elderly people (65 and older) fall. In fact, one out of three elderly people falls each year, but less than half tell their doctor. Falling once doubles the chances of falling again [12]. Each year, 2.5 million elderly people are treated in emergency departments for fall injuries, and absolute numbers are on the rise. Falls remain the leading cause of injury-related hospitalizations among Canadian seniors, and between $20 \%$ and $30 \%$ of seniors fall each year. Falls and associated outcomes not only harm the injured individuals but also affect family, friends, caregivers and the healthcare system [13].

Fall consequences are serious and costly. Falls can have severe consequences such as injury or death; in 2014 in the United States 33,018 elderly people died from fall-related injuries [12,14]. One out of five falls causes a serious injury such as broken bones or a head injury $[15,16]$. Over 700,000 patients a year are hospitalized because of a fall injury, most often because of a head injury or hip fracture, according to the Centers for Disease Control and Prevention [12]. Each year at least 250,000 elderly people are hospitalized for hip fractures [17]. More than $95 \%$ of hip fractures are caused by falling [18], usually by falling sideways [19]. Falls are the most common cause of traumatic brain injuries (TBI), and the direct medical costs for fall injuries are $\$ 34$ billion annually in the US. Hospital costs account for two-thirds of the total [20].

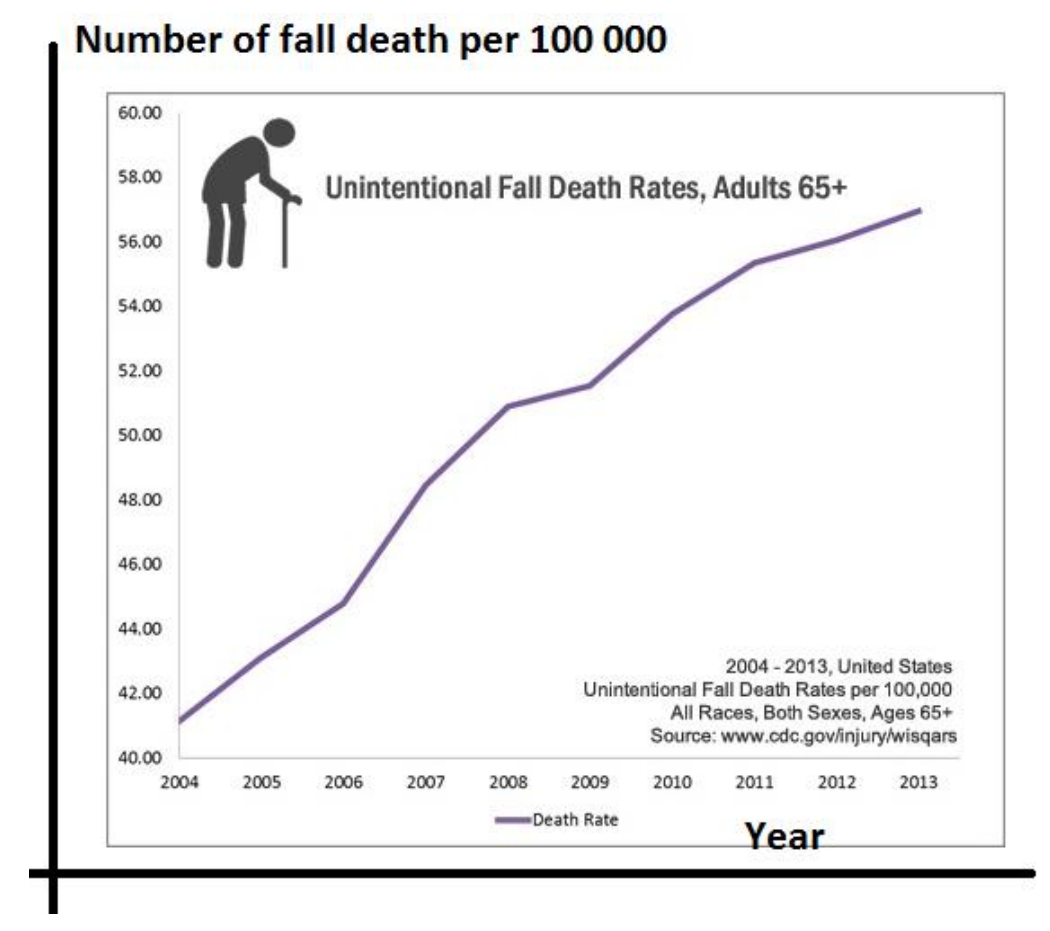

Figure 1. Fall deaths between 2004 and 2013 in the US adapted from [12].

These injuries can make it hard for elderly people to get around, do daily activities, or live independently (loss of autonomy). Falls can also cause broken wrists, arms, and ankles. According to the Public Health Agency of Canada [13] one-third of fall-related hospitalizations among elderly people were associated with a hip fracture. The report of the Public Health Agency of Canada also shows that elderly people who were hospitalized because of a fall spent approximately three weeks in the hospital, three times more than the average hospital stay in Canada among all ages. This discrepancy highlights the disproportionate healthcare costs of fall-related injuries in comparison to other causes of 
hospitalization. Even more worrying is that the number of deaths due to falls is increasing. Figure 1 shows the increasing number of deaths caused by falls from 2004 to 2013 in the US [12]. Figure 2 shows the increasing number of fall-related hospitalizations in Canada for elderly people (65+) by gender and age group for the year 2011 [13]. Falls of elderly people can be very serious, especially if the person is taking certain medicines (such as blood thinners) [12]. Many elderly people who fall, even if they are not injured, become afraid of falling. This fear may cause a person to cut down on their daily life activities which leads to social isolation. When people are less active, they become weaker and this increases their chances of falling [21].

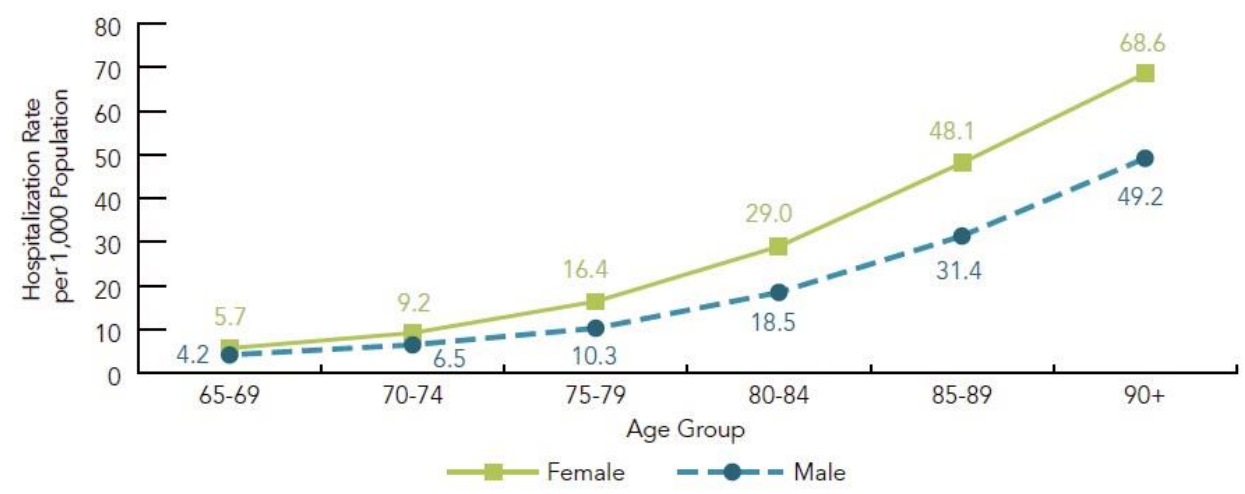

Figure 2. Fall-related hospitalization in Canada by gender and age group, age 65+, Canada, year 2011 [13].

Statistical studies indicate that the majority of fall accidents are indoor falls (homes and residential institutions). The Public Health Agency of Canada [13] reveals that half of the falls of elderly people occur at home, and $17 \%$ in residential care institutions (Figure 3).

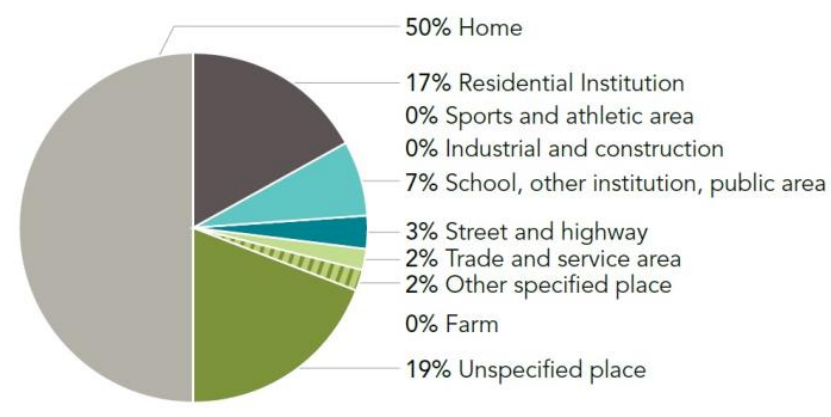

Figure 3. Fall-related hospitalizations, by place of occurrence of fall, age 65+, Canada [13].

Most falls occur as a result of compounding factors that combine and overwhelm an elderly person's ability to maintain balance. These factors typically represent a complex interaction of biological, behavioral, environmental and socio-economic conditions termed "risk factors" [13]. Research has identified numerous conditions that differentiate between elderly people who fall and those who do not fall. Each elderly person may face a unique combination of risk factors based on life circumstances, health status, health behaviors, economic situation, social supports and the environment.

Understanding what puts a person at risk of falling is a critical step in reducing falls and fall-related injuries among elderly people [13]. Many risk factors can be changed or modified to help prevent falls. These risk factors include: lower body weakness, vitamin D deficiency, difficulties with walking and balance, and use of certain medicines. Even some over-the-counter medicines can affect balance; vision problems, foot pain or poor footwear, home hazards or dangers such as broken or uneven steps and no handrails along stairs or in the bathroom are additional risk factors [12]. 
In order to cope with the risk of falling for elderly people living in community and healthcare facilities, human interventions to prevent fall risks were applied. Group and home-based exercise programs (e.g., Tai Chi training) and home safety interventions reduce the rate of falls and the risk of falling. Vitamin D supplementation does not appear to reduce falls but may be effective for elderly people who have lower vitamin D levels [22].

Although these interventions reduced the fall risk to a certain extent, they require a high cost and are associated with a burden on elderly people and on the healthcare system budgets. In addition, the interventions to prevent fall risks have to be accompanied by technological solutions to detect falls automatically in order to proceed and provide the necessary and fast interventions to rescue elderly people when falling, because falls are still likely to occur, and the falls must be quickly detected to prevent further injury to the fallen elderly people.

\subsubsection{Ambient Assistive Technology for Indoor Fall Risk}

Ambient assistive technology can help physical therapists and caregivers to clearly know the circumstances of falls, allowing for better caregiving to elderly people. To address fall risk, the Personal Emergency Response System (PERS) [23,24] represents a commercial solution. These clinical alarm systems enable elderly people who fall to contact an emergency center by pressing a button. While appropriate in many situations, the PERS system becomes useless if the person is unconscious or unable to reach the button. Even when the system is available, a study revealed that around $80 \%$ of elderly people wearing a PERS did not use their alarm system to call for help after experiencing a fall [25].

To cope with the challenges associated with PERS systems, passive monitoring solutions have been proposed to automatically detect falls and call the caregiving centers. Elderly people found that the use of tele-monitoring gives them a greater sense of security and enables them to stay at home longer [23]. Several solutions are currently available, with most being devices worn by a person (e.g., a smart watch or attached to clothing). Other solutions include technologies embedded in the residential setting such as cameras, microphones or pressure sensors installed under the floor [23].

A systematic review performed by Chaudhuri et al. [23] about fall detection devices and their usage categorizes fall detection ambient assistive technology into two categories: wearable and non-wearable systems. Wearable systems generally consist of placing an accelerometer sensor (kinematic-based systems) on elderly people to detect changes in acceleration and planes of motion to identify falls [26-30]. The most common location for wearable devices was the trunk of the body (chest, waist, thorax, etc.). Other devices were placed near the head, arms, hands or feet of elderly people [23]. Sensors integrated in smart phones are considered wearable sensors [31] (e.g., accelerometers, gyroscopes, and magnetic field sensors). The tri-axial accelerometer is the most used sensor for smartphone-based fall detection systems. Non-wearable systems include: (1) cameras and vision-based approaches [32-34] (a single camera, or multiple-camera networks); and (2) ambient sensor-based approaches (e.g., motion detectors involving infrared sensors that identify motion, acoustic sensors [35,36], pressure sensors [37] that are placed in elderly people's environment and use various measurements to determine if a person has fallen). Chaudhuri et al. [23] identified 57 projects using wearable systems and 35 projects involving non-wearable systems. Other systems used multiple sensors to detect a fall. Multiple sensors can be any combination of two or more sensor types used to monitor a person.

Specific fall detection algorithms based on artificial intelligence techniques are used based on the type of data captured by the sensors. Yu [38] presents a survey on approaches and principles of fall detection for elderly people. Yu first identifies the characteristics of falls from sleeping, sitting and standing and categorizes fall detection methods based on wearable, computer vision and ambient devices. These approaches were further developed into specific techniques such as those based on motion analysis, posture analysis, proximity analysis, inactivity detection, body shape and 3D head motion analysis. Yu mentions that a fall is a rare event and it is important to develop techniques 
to deal with such scenarios, and then addresses the need for generic fall detection algorithms and fusion of different sensory data such as wearable and vision sensors in order to provide better fall detection systems. Fall detection algorithms are either threshold-based (fixed or adaptive), or based on machine learning or activity recognition techniques. Smartphone-based fall detection systems are mostly threshold-based [39]. Machine learning algorithms include: one-class support vector machine, one-class K-nearest neighbor, and unsupervised/semi-supervised/supervised machine learning techniques. We illustrate the framework of assistive technology for fall risk in Figure 4.

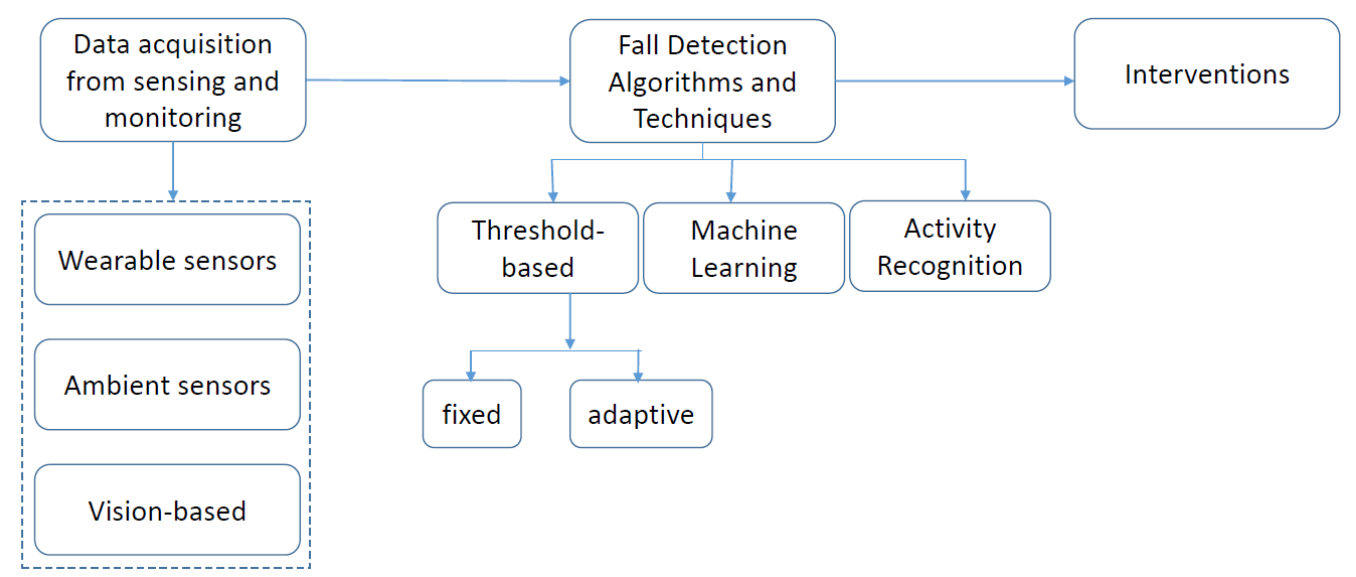

Figure 4. Framework of ambient assistive technology for fall risk.

Khan et al. [9] present a taxonomy of fall detection techniques based on two high-level categories from the data availability perspective: (I) sufficient training data for falls; and (II) insufficient or no training data for falls. The first category (I) of this taxonomy presents the case where sufficient data for falls is available to train the classifiers. In this category, due to the presence of sufficient falls and normal ADL data, different algorithms based on thresholds, supervised machine learning and one-class classifiers (trained on sufficient fall data) can be employed [9]. This category represents an optimistic view of the difficult problems of fall detection, due to their rarity and difficulties in the data collection process in real-world situations. The approaches in the first category (I) attempt to detect a fall directly given their training data, whereas the approaches in the second category (II) either manipulate the little available fall data or try to indirectly detect a fall as an abnormal activity given (almost) no training data [9].

We classify assistive technology for fall risks according to two criteria: system components (wearable devices or non-wearable devices) and the basic principles of fall detection algorithms/techniques (sufficient data for fall detection or insufficient data). We cite representative examples of fall detection algorithms and techniques from both categories and for wearable and non-wearable devices.

a. Wearable devices with sufficient training data for fall detection

Most of the research work in fall detection deals with applying supervised classification methods. We briefly cite representative examples of systems where fall detection is based on threshold identification, one-class classification, and sequential classification methods [9].

Several research works in fall detection are based on thresholding techniques [40-43] where raw or processed sensory data is compared to a single threshold or multiple pre-defined thresholds to detect a fall. Sposaro and Tyson provide a fall detection system named "iFall" based on the accelerometer sensor of a smartphone [44]. The fall detection algorithm uses an adaptive threshold which changes with user-provided parameters such as height, weight and level of activity. The system generates the final decision by automatically analyzing the difference in position data before and after the suspected fall event. An example of a fixed threshold-based fall detection algorithm is the algorithm used in 
a mobile application named "Sensorfall" which uses an accelerometer sensor of a smartphone to be placed in trouser pocket [45]. However, a mobile phone is rarely held by elderly people during indoor ADL. Perry et al. [46] present a survey on real-time fall detection methods based on techniques that measure only acceleration, techniques that combine acceleration with other methods, and techniques that do not measure acceleration. They conclude that the methods measuring acceleration are good at detecting falls. They also comment that the placement of a sensor at the right position on the body can impact the accuracy of fall detection techniques. Most of these techniques need training data for falls and depend on either domain knowledge or data analysis techniques to compute thresholds for their identification. Few fall detection systems are based on measuring falls pre-impact which may enable preventing falling injuries in the future by using additional equipment such as airbags which would inflate right before the fall $[47,48]$.

Other fall detection algorithms are based on one-class classifiers such that the classifier can be trained on falls to reject normal activities, where sufficient training data for falls is available. Zhang et al. [49] train a one-class Support Vector Machine (SVM) from falls and outliers from non-fall ADL and show that falls can be detected effectively.

Sequential classification algorithms are based on the principle that people follow certain natural regularities and temporal smoothness while performing ADL. So, the recent history of activities can help to predict the present type of activity. Using a sequence of probabilities computed through static classifiers and training the Hidden Markov Model (HMM) on them can significantly improve the performance and smoothness of the activity recognition system [50]. Tong et al. [51] use the time series from human fall sequences collected using a tri-axial accelerometer worn on the upper body. A Hidden Markov Model (HMM) is trained on events just before the collision for early fall prediction. They also compute two thresholds for fall prediction and detection to tune the accuracy. Florentino et al. [52] present a hierarchical HMM-based method to detect human activities including falls using a tri-axial accelerometer. Their technique is sensitive to the placement of the sensor on the person's body. In another paper, they extend this method by proposing a sensor position-invariant measure on the raw accelerometer signal with the assumption that the sensor is placed in any fixed location within a region approximately bounded by a belt at the waist and a trouser pocket, which enabled them to improve the precision. The proposed method reduced sensitivity to the position and orientation of the sensor on the body. The inputs to the classification algorithm are made invariant to sensor orientation, despite the signals being recorded from arbitrary sensor placements [53].

b. Wearable devices with insufficient training data for fall detection

Certain wearable device systems identify falls as abnormal activity due to the lack of availability of sufficient data for falls and the lack of knowledge and understanding of falls. Considering a fall as an abnormal activity is an important research area, because this reflects the real-world situation where falls happen infrequently [9]. Yin et al. [54] propose a two-stage abnormal activity detection method in which a one-class SVM is first trained on normal activities and the abnormal activities are filtered out to derive abnormal activity models from a general normal activity model in an unsupervised manner. The method iteratively detects different types of abnormal activities based on a threshold. They claim that this method provides a good trade-off between false alarms and abnormal activity detection without collecting and labeling the abnormal data. The data is collected by using wearable sensors attached to a person and abnormal instances were collected by simulating falls and slipping in different positions.

\section{c. Non-wearable devices with sufficient training data for fall detection}

Non-wearable devices were often set up in a room where elderly people would either walk around or live. Yu et al. [55] introduce a video-based fall detection system for elderly people. They extract several video features and apply one-class classification techniques to determine whether the new instances are in the "fall region" or outside it to distinguish a fall from other activities such as walking, 
sitting, standing, or lying. Han et al. [56] establish a "WiFall" system to detect indoor falls for elderly people based on the advanced wireless technologies that employs the time variability and special diversity of channel state information (CSI) as the indicator of human activities. Zhang et al. [57] establish a fall detection system named "Anti-Fall" based on the CSI phase difference over two antennas. They exploit both the phase and amplitude to increase the accuracy of fall detection and separate the fall from other fall-like activities.

\section{d. Non-wearable devices with insufficient training data for fall detection}

We cite representative examples of non-wearable systems that consider falls as abnormal activity and require training data from normal activities to learn the models to identify abnormal activities. Khan et al. [58] propose an unsupervised acoustic fall detection system with interference suppression that makes use of the features extracted from the normal sound samples, and constructs a one-class support vector machine model to distinguish falls from non-falls. They show that their interference suppression technique makes the fall detection system less sensitive to interferences by using only two microphones. Parisi and Wermter [59] propose a hierarchical self-organizing maps (SOM)-based architecture for the detection of novel human behavior in indoor environments by learning normal activities in an unsupervised manner using SOM. The system considers novel behavior as abnormal. This technique can be adapted for elderly people fall detection in an indoor environment.

\subsubsection{Discussion}

An extensive research work has been performed in the area of fall detection using a variety of solutions [23]. These devices can measure different aspects of the fall velocity, the impact and the posture of the faller. Each type of device appears to have its own strengths coupled with certain weaknesses. Wearable devices, if used properly, are always with people and can easily detect the acceleration or the impact experienced by the faller. However, these devices are reliant on the person not only remembering to wear the device but also choosing to wear the device, which can be especially difficult and not convenient at nighttime [60]. These devices depend also on battery power and can suffer from false alarms due to impact or changes in acceleration not caused by falls. Non-wearable systems, on the other hand, do not rely on the person to remember to use the system. Instead they are able to survey a certain area while hardly affecting the person. However, these systems are limited to a specific space and suffer from aspects of privacy concerns [61]. Cameras, with their ability to take full photos or videos of people, have been seen as intrusive. These systems suffer from problems with occlusion (having the person blocked by another object in the room) [62]. A solution is to use multiple sensors to cope with the weaknesses in each device. For example, coupling a camera system with a wearable system would account for the person leaving the space of the camera or the person forgets to wear the device at night. However, adding more and more devices could overwhelm elderly people, causing them to reject such systems. Many studies have shown that elderly people are favorable to such systems and find that the use of these devices can give them a greater sense of security $[63,64]$.

On the other hand, traditional fall detection techniques assume sufficient data for fall detection. Considering a fall as an abnormal activity is an important research area, because this reflects the real-world situation where falls happen infrequently [9].

Table 2 summarizes our classification of assistive technology for fall risk according to sensors and fall detection algorithms and techniques. 
Table 2. Assistive technology for fall risk: sensors and fall detection algorithms/techniques.

\begin{tabular}{|c|c|c|c|c|}
\hline & Wearable Dev & & Non-Wearable Devices & \\
\hline \multirow{4}{*}{$\begin{array}{l}\text { Sufficient } \\
\text { training data }\end{array}$} & Fixed threshold & {$[45]$} & \multirow{3}{*}{$\begin{array}{l}\text { Vision-based sensors/one class } \\
\text { classification to distinguish fall } \\
\text { from other activities. }\end{array}$} & \multirow{3}{*}{ [55] } \\
\hline & Adaptive threshold & [44] & & \\
\hline & one-class SVM & [49] & & \\
\hline & $\begin{array}{c}\text { Sequential } \\
\text { classification (HMM) }\end{array}$ & {$[50,51]$} & $\begin{array}{c}\text { Channel State Information (CSI) } \\
\text { of WiFi signals }\end{array}$ & {$[56,57]$} \\
\hline \multirow{2}{*}{$\begin{array}{l}\text { Insufficient } \\
\text { training data }\end{array}$} & \multirow{2}{*}{$\begin{array}{l}\text { Fall as abnormal } \\
\text { activity }\end{array}$} & \multirow{2}{*}[54]{} & Acoustic sensors/one class SVM & {$[58]$} \\
\hline & & & Self-Organizing Maps & [59] \\
\hline
\end{tabular}

\subsection{Risk of Wrong Self-Medication Management (Non-Adherence, Abuse and Misuse)}

Elderly people are subjected to several problems when taking medications: they forget to take their medications at the proper times, take the incorrect amount of medication at the proper time, overdose on their medication by taking it more than once because they forget that it has already been taken, do not take medication on purpose because they are uncertain if they have already taken it, do not remember which medication is the correct one to take at the proper time [65].

Adherence to (or compliance with) a medication regimen is generally defined as the extent to which patients take medications as prescribed by their healthcare providers. Compliance is defined as "remembering to take a dose" and adherence to medication regimens as "taking doses at the prescribed time" [66]. Generally speaking, the terms "adherence" and "compliance" to medications are used interchangeably in the literature. Adherence is important for obtaining or maintaining improved health of patients with chronic diseases or severe health conditions. Typically, elderly people are prescribed different types of medications, which must be taken in varying dosages. Kulkarni [65] reveals that 25\% of elderly people use four or more prescriptions on a daily basis. Elderly patients must keep track of the correct times at which they are supposed to take these medications. $55 \%$ of elderly people fail to comply with medication regiments, and $50 \%$ of all prescriptions are taken incorrectly. Studies show that $58 \%$ of elderly people make errors in taking medications, and of these errors $26 \%$ are potentially serious according to their doctors [65].

Adherence to prescribed medication regimens is difficult for all patients and particularly challenging for elderly people [67]. Clinical studies report that the average medication adherence ratio is between $43 \%$ and $78 \%$ among elderly people who are frequently taking medications for chronic illnesses [68]. Elderly people are among the most vulnerable to medication non-adherence and misuse because they use more prescription and over-the-counter medications than other age groups [69]. Elderly patients use prescription medications approximately three times as frequently as the general population [70]. Elderly people are at high risk for medication misuse due to conditions such as pain, sleep disorders, and anxiety that commonly occur in this category of age. They are, therefore, more likely to receive prescriptions with potential for misuse and abuse. Approximately $25 \%$ of elderly people use psychoactive medications that have the potential to be misused and abused [71]. Elderly people are more likely to use psychoactive medications for longer periods than younger adults, and longer periods of use increase the risk of medications misuse and abuse [72]. In addition to concerns regarding the misuse of medications alone, the combination of alcohol and medication misuse has been estimated to affect up to $19 \%$ of elderly Americans [73]. The potential health consequences of the misuse of psychoactive and alcohol medications are numerous (e.g., depression and cognitive decline). Therefore, medication misuse constitutes a high risk for elderly people and can lead to memory impairments, and problems in exercising ADL and social activities [71]. The problem of medication non-adherence is large and costly for American health providers [74]. Statistical studies reveal that patient non-adherence costs the healthcare system $\$ 100$ billion per year in additional 
hospital stays, and it has been estimated that better adherence to antihypertensive treatment alone could prevent 89,000 premature deaths in the United States annually [74].

Chronic conditions (e.g., depression, dementia) that affect cognition abilities of elderly people are associated with problems in medication self-management [75]. Forgetting to take medication is a frequent problem [76]. Age, frailty, and physical and sensory impairments (particularly vision impairments) can interfere with opening medication bottles or blister packs and reading labels and educational materials [77]. Living with family is helpful when family members remind elderly people to take medicine or assist them with tasks related to medication management [78]. Preventing prescription medication misuse and abuse requires a coordinated system of care that integrates medical and physical health, behavioral health, and the aging services networks to fully address this growing problem [69].

Many elderly people live alone and do not have anyone at home to provide care [7]. Also, living at care facilities or nursing homes may have negative impacts on elderly people including an emotional impact (e.g., it reduces the private space of elderly people) and economic impact (e.g., it is often associated with a cost to the person, the family or the health system). Therefore, ambient assistive technology is an essential solution to reduce the harmful effects of medication non-adherence and misuse.

\subsubsection{Ambient Assistive Technology for Wrong Self-Medication Management Risk}

Assistive technology for medication adherence is a part of ubiquitous healthcare (U-Health) smart home technology [79]. There are a variety of wearable sensors and devices available for monitoring a patient's health status: (e.g., a blood glucose sensor is capable of continuously monitoring the blood glucose level, and an electrocardiography sensor can measure the activity of the heart). The detection of health or safety problems is achieved by analyzing and correlating the physiological data collected from these sensors with some environmental information (e.g., localization). Design requirements for these types of wearable sensors are very important in order to be acceptable by elderly people and to address their medical needs. The sensors need to be easy to wear and configure, and should present a minimal inconvenience to people. We reviewed in detail the existing assistive technology for health issues of elderly people in our papers [80,81]. In this paper we focus on ambient technology to assist elderly people against wrong self-medication management (non-adherence, misuse, and abuse).

Assistive technology for medication adherence is based on pervasive automatic reminders for medication use. Monitoring devices have likely increased the access to several data sources concerning medication adherence information. We cite representative techniques to detect and measure medication adherence for elderly people. It is difficult to determine medication adherence without specialized monitoring devices. With the electronic pillbox named "MedTracker" [82], whenever the user opens a sub-compartment lid on the pillbox, the plunger releases a switch inside the device, sending a signal to the microcontroller indicating that the door was open. The "SmartPillBox" [65] is another example of electronic pillboxes that are filled with the prescribed medications; the schedule for medication consumption is stored in it, and the weight of the total number of pills is weighed automatically by the SmartPillBox and stored. Each time a pill is taken, the SmartPillBox registers the change in weight of the pills and uses this information to mark the time the pill was taken, and from the change in the weight of the remaining pills it calculates how many pills were taken. The SmartPillBox reminds the patient to take the prescribed medication, and sends information using a telephone line to external systems to store the information of the patient's compliance. This information will be processed by the external system. For example, the system can alert a nurse or a caregiver if the patient is not compliant.

Medication event monitoring systems (MEMS) [83] are electronic devices simulating a pharmacy vial that displays information about the date and time of opening the vial and it can be programmed to alert the patient to take medication. Data can be downloaded via a communicator for interpretation. A medication event monitoring system operates through the Internet, interconnecting and accommodating the transfer of information and data between a patient, a caregiver, and a 
pharmacist. A control center is provided in the intercommunication with the patient center, caregiver and pharmacist for accommodating the exchange of information and data regarding medication usage between the persons of interest. The patient center also includes physical sensing devices, such as for blood pressure and temperature. Elderly patients communicate through a smartphone, and further communicate through pill-dispensing devices in a docking system that is in intercommunication with the various centers. The pill-dispensing devices accommodate pills of various sizes and shapes to be easily used by a patient, and have associated sensing and recording devices to ensure that the medication is taken in the appropriate quantities and at the appropriate time. MEMS provide excellent information about adherence and offer several advantages in assessing adherence; however, they have certain limitations. First, opening a medication vial does not necessarily mean the dose was taken [67]. Second, MEMS do not report adherence in real time, so intervention cannot take place if medications are missed [84]. Third, the MEMS cap is difficult to open for arthritic hands [85,86]. Fourth, MEMS do not accommodate the use of pill boxes for sorting medications into daily doses, as commonly done by elderly people [87]. Finally, the price may be prohibitive for individual patient use, particularly when multiple medications are involved [67].

Other medication management monitoring devices are ingestible microchips embedded in the medication which transmit a signal when the medication is ingested or even metabolized. DiCarlo [88] developed a system for medication adherence using an ingestible electronic sensor attached to a tablet. After ingestion, the sensor separates from the medication, activated by gastric fluid, and communicates with the monitor that is worn on the user's torso. The information stored in the monitor is sent wirelessly using Bluetooth to a mobile phone. Several apps for Android and Apple mobile devices enable healthcare providers to communicate with patients in real time about their medications and, with the help of Radio Frequency Identification (RFID) tags or bar codes on drug packaging, the application verifies that patients have taken their medications as prescribed [89].Wan [90] proposed the "Magic Medicine Cabinet" which is based on RFID to identify which medications were taken out of a cabinet, with face recognition to identify who approached the device, and a broadband connection to be able to provide an integrated "situation health portal". Thus, patients were required to use the medicine cabinet and to store all medications in separate bottles that could be RFID tagged. Fishkin et al. [91] proposed a lighter-weight version of the medicine cabinet, in which RFID-tagged bottles were kept on a monitoring pad that incorporated an RFID tag reader and a scale for determining how much medication had been taken. Yamamoto et al. [70] propose a medication management assistive system for the care of elderly people at home with the following main functionalities: RFID-based medication management; RFID and wireless sensor-based monitoring for taking medication; and a situation awareness and decision-making-based approach for assistance in taking medication. The system reminds an elderly person to take medications at a predicted time based on learning the person's habits and regular meal-taking schedule. The inference of the reminder time is based on a fuzzy logic technique. Vinjumur et al. [92] establish a Web-based medicine intake tracking application using RFID tags to monitor drug taking patterns for elderly people and the consequences are reported to caregivers. The application uses RFID readers and tags, motion sensors, and a wireless sensor mote. Caregivers monitor medication adherence via a Web-based caregiver module.

Examples of reminder devices to take medications and which may provide intervention techniques include machines that dispense medication, voice-mail reminders, video-telephone reminders, automated telephone calls, and medication caps equipped with digital alarm clocks [93-96]. Automated medication dispensers give a patient access to the correct medication at the prescribed time. As an example, the MD2 is a medication-dispensing system [97] that stores up to 60 plastic reusable cups, preloaded in a locked compartment. At preprogrammed intervals, the patient presses a large red exterior button, and a plastic cup containing the medications appears in a chute. Reminders are both audible (spoken words and tones) and visual (a flashing red strobe light). If a patient does not push the dispensing button after the first prompt, the machine continues prompting every three minutes for $45 \mathrm{~min}$. If after $45 \mathrm{~min}$ the patient does not push the dispensing button, the machine notifies an 
identified responder (either a family member or a caregiver). Health Buddy is a pager-like device to remind patients to take their medications. The device asks interactive questions to patients about medication use. Then the patient's answers are transferred to caregivers. Beep $\mathrm{N}$ Tel is a device that gives an audible notification via the vial cap to remind a patient to take medication. This device records messages by caregivers to instruct patients with the appropriate recommendations. HealthWatch is a digital watch that works with a personal computer. It displays up to eight reminders per day and a text message for each reminder. Home monitoring services include scheduled devices that remind patients to take their medication. If the device is not touched by the patient (indicating that the dose has not been taken), the patient is called on the telephone or a caregiver can be contacted [67].

Online compliance reports are provided to monitor missed doses. However, the previous systems do not engage patients in shifting their behavior towards better medication compliance. Most of the strategies that address medication adherence and compliance involve reminding patients to take their pills and educating them on the effects of non-compliance, which do not seem to be enough to motivate people to comply with their medication regimens [98]. Alerting patients to do the same thing every day does not engage them in actually doing it by themselves. Persuasive technology is another category of systems to improve medical adherence in elderly patients. MoviPill [66] is a mobile phone-based game that persuades elderly patients to be more adherent to their medication prescription by means of social competition. Increasing levels of focuses on changing the way elderly people perceive the drug intake task. The idea of MoviPill is that patients become more compliant in taking their medications when the task is not seen as an obligation, but rather as an entertaining and engaging experience. MoviPill encourages compliant behavior by giving more points to players that take their medication very close to or at the prescribed time, and less or no points otherwise. The game includes a social competition by connecting all players through a social network and allowing them to check how disciplined they are in regard to the other competitors. Experimental results in [66] showed that MoviPill helped to improve medication adherence when participants played the game.

Despite the moderate success of various interventions to improve medication adherence in elderly people, few studies have attempted to translate these results specifically to elderly people with cognitive impairment. Improving medication adherence for elderly people with cognitive impairments requires that interventions provide a frequent interaction on a continuous basis to have a positive impact on adherence, and should be delivered by a significant degree of human communications [99]. Table 3 summarizes the technology systems that assist elderly people to adhere to their prescribed medications. Figure 5 illustrates the framework of ambient assistive technology for medication adherence.

Table 3. Examples of ambient assistive technology systems for self-medication management.

\begin{tabular}{|c|c|c|}
\hline System & $\begin{array}{l}\text { Monitoring and Detection of } \\
\text { Medication Adherence }\end{array}$ & Interventions \\
\hline SmartPillBox [65] & Pill count/weight. & $\begin{array}{l}\text { Reminds patients to take the prescribed medications, } \\
\text { and contacts caregivers through telephone to store } \\
\text { the information of the patient's compliance. }\end{array}$ \\
\hline $\begin{array}{l}\text { Electronic pillboxes, } \\
\text { MedTracker [82] }\end{array}$ & $\begin{array}{l}\text { Opening lid of a sub-compartment of } \\
\text { the pillbox. }\end{array}$ & Not found in the paper. \\
\hline $\begin{array}{l}\text { Medication Event } \\
\text { Monitoring Systems } \\
\text { (MEMS) [83] }\end{array}$ & $\begin{array}{l}\text { Associated sensing and recording devices. } \\
\text { Displays information about the date and } \\
\text { time of opening the vial. }\end{array}$ & $\begin{array}{l}\text { It can be programmed to alert patients to take } \\
\text { medication. A medication event monitoring system } \\
\text { operates through the Internet, interconnecting and } \\
\text { accommodating the transfer of information and data } \\
\text { between a patient, a caregiver, and a pharmacist. }\end{array}$ \\
\hline Ingestible sensor [88] & $\begin{array}{l}\text { Ingestible sensor microchips embedded in } \\
\text { medication transmit a signal when the } \\
\text { medication is ingested or } \\
\text { even metabolized. }\end{array}$ & $\begin{array}{l}\text { The sensor communicates with the monitor that is } \\
\text { worn on the user's torso. The information stored in } \\
\text { the monitor is sent wirelessly using Bluetooth to a } \\
\text { mobile phone. }\end{array}$ \\
\hline
\end{tabular}


Table 3. Cont.

\begin{tabular}{|c|c|c|}
\hline System & $\begin{array}{l}\text { Monitoring and Detection of } \\
\text { Medication Adherence }\end{array}$ & Interventions \\
\hline $\begin{array}{l}\text { Magic Medicine } \\
\text { Cabinet [90] }\end{array}$ & $\begin{array}{l}\text { RFID to identify which medications were } \\
\text { taken out of a cabinet, face recognition to } \\
\text { identify who approached the device. }\end{array}$ & Reminds patients to take medication. \\
\hline $\begin{array}{c}\text { Medication } \\
\text { management [70] }\end{array}$ & $\begin{array}{l}\text { RFID- and wireless sensors-based } \\
\text { medication taking monitoring; situation } \\
\text { awareness and decision-making. } \\
\text { The inference of reminding time is } \\
\text { based on fuzzy logic. }\end{array}$ & $\begin{array}{l}\text { Reminds an elderly person to take medications in a } \\
\text { predicted time based on learning person's habits and } \\
\text { regular meal-taking schedule. }\end{array}$ \\
\hline $\begin{array}{l}\text { Web-based medicine } \\
\text { intake tracking } \\
\text { application [92] }\end{array}$ & $\begin{array}{l}\text { RFID readers and tags, motion sensors, } \\
\text { and a wireless sensor mote. }\end{array}$ & A Web-based caregiver module. \\
\hline MoviPill [66] & Persuasive technology. & $\begin{array}{l}\text { A mobile phone-based game that persuades elderly } \\
\text { patients to be more adherent to their medication } \\
\text { prescription by means of social competition. }\end{array}$ \\
\hline
\end{tabular}

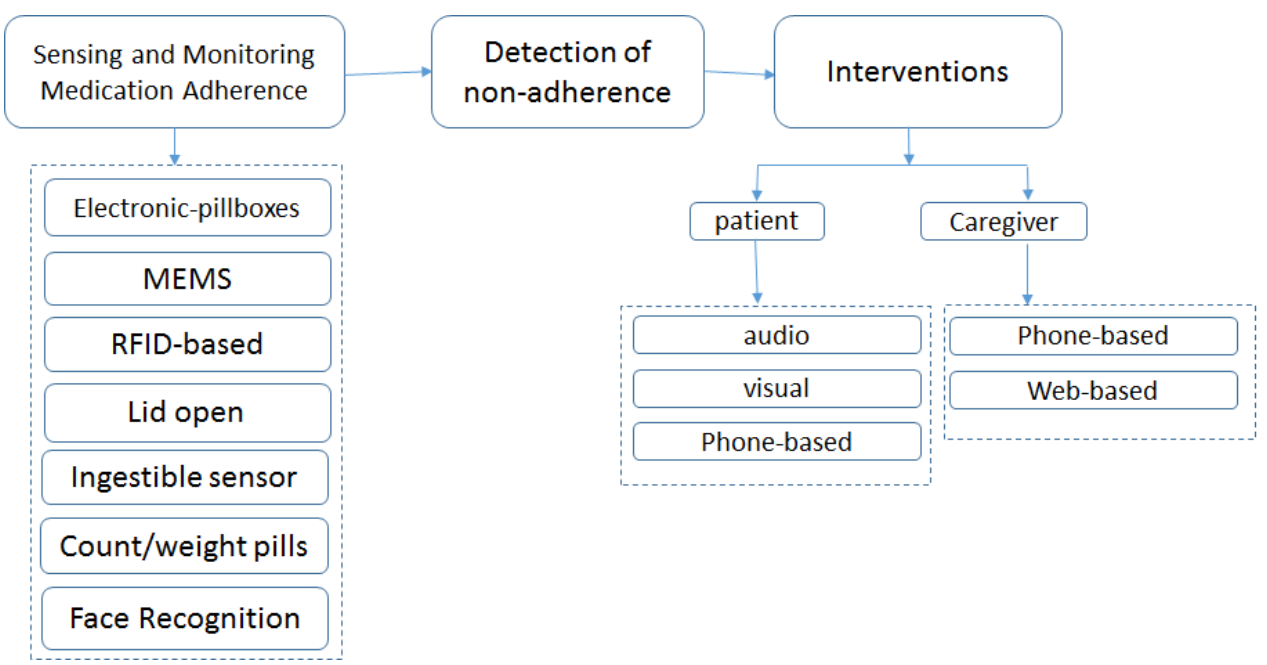

Figure 5. Framework of ambient assistive technology for self-medication management.

\subsubsection{Discussion}

The deviation of elderly patients from their prescribed medication regimen constitutes a high risk. Therefore, keeping elderly patients adherent to their prescribed medication is essential to ensure patient safety. The existing ambient technology systems for assisting elderly people to adhere to their prescribed medications are based on automatic reminders (audio, visual, phone) and monitoring medication adherence through several techniques (e.g., sensors to detect if the lid of the electronic pillbox is open, number/weight of pills has changed, ingestible sensor embedded in medication, RFID readers and tags, motion sensors, face recognition). When the system detects a non-adherence situation, it alerts the patient and/or notifies the caregivers. Other technology solutions are based on persuasive technology to motivate elderly patients to adhere to their prescribed medications. However, no single system is sufficiently accurate or reliable. Thus, a combination of techniques is preferred. In addition, energy efficiency is an important issue to be considered for ambient assistive technology systems. 


\subsection{Risks of Fire, Burns and Intoxication by Gas/Smoke}

\subsubsection{Risk of Fire}

Fires cause injuries and loss of human life. In the United States, occupational fatalities account for more than 3\% of all deaths related to fires [100]. The Centers for Disease Control and Prevention (CDC) revealed that in 2014, residential fires caused 1229 deaths among elderly people out of a total 2400 residential fire deaths in the USA [14]. Residential fire also causes huge financial losses, for example property losses due to all the fires in the United States were estimated to be almost $\$ 8$ billion in 1995 [101]. Elderly people are at higher risk for house fire death for several reasons: they are known to have a lower prevalence of smoke detectors and they usually forget to replace batteries in fire detectors, physiological and cognitive decline (e.g., hearing impairment) means they may not hear the smoke alarm, restricted mobility means they may be slow or unable to escape, using old appliances such as portable heaters or heating blankets increase the risk of fire, as does living in older homes. These factors introduce a higher risk of house fires. A survey conducted by Runyan et al. [102] revealed that the death rate due to fire/burns is higher among elderly people in the United States. This study also reported that $97 \%$ of the participants in this survey have a smoke alarm, $80 \%$ have one smoke alarm on each level of their home, $71 \%$ reported having a fire extinguisher and $51 \%$ of the participants living with at least another person had a fire escape plan. Runyan et al. conclude that there is a need for adopting measures for fires and burn prevention such as using fire extinguishers and having escape plans. Several research studies reveal that the kitchen is the second place where the majority of domestic accidents occur, and in particular the oven presents the main source of fire accidents in residences [103,104]. Studies revealed that unattended cooking is the main leading factor responsible for fires in the kitchen $[103,105,106]$. Following is an example that illustrates the gravity of the situation [107,108]. Elderly people often put a pot on an oven burner, and engage in other activities (e.g., watch television, sleep, call another person), forgetting the pot on the burner. This situation, which is due to attention and memory problems, may cause a fire and lead to catastrophic results (e.g., death of the elderly people). Hence, enabling kitchen safety is a major factor for elderly people to live independently.

According to the U.S. Fire Administration [109] cooking accidents are the leading cause of fire-related injuries for elderly people in the United States. Specialized organizations have made suggestions for elderly people who cook their meals by themselves to consider safety measures in the kitchen. Fire prevention approaches for elderly people are highly important. Measures include encouraging the purchase and maintenance of smoke detectors, selecting alarms with a louder signal, placing the alarm closer to the sleeping area, selecting alarm systems with an alternative inaudible method of indicating smoke, planning escape assistance with neighbors and ensuring the safety of home appliances [110].

Other sources of fire risk at home are due to faulty electrical wiring and overloaded outlets, particularly in old houses where wiring is unable to support the intensive electric current of new appliances. Recommendations are to unplug electrical appliances that are not frequently used and to install ground fault circuit interrupters in order to prevent fire accidents caused by electric appliances [111].

\subsubsection{Risk of Burns}

Elderly people are more prone to burn deaths than other age categories and the nonfatal burn injury ratio is higher among elderly people $[14,112,113]$. Each year in the United States, approximately 45,000 individuals are hospitalized for the treatment of a burn injury. This number also includes the approximately 25,000 individuals whose burns are very severe according to the American Burn Association [114]. The National Center for Injury Prevention and Control [14] reveal that the number of elderly people who died due to burns with hot objects/substances reached 46 in the U.S in the year 2014. Hot tap water is a major cause of scalds and that scalds are often more severe than other types 
of scalds, because this may involve larger portions of the body $[102,112]$. The home is the principal environment in which burns and fire-related injuries occur $[115,116]$.

Tap water that is above $120^{\circ} \mathrm{F}\left(\approx 49^{\circ} \mathrm{C}\right)$ represents a scald hazard for elderly people [102,113]. Maintaining tap water at $120^{\circ} \mathrm{F}$ is a successful strategy for reducing scalds $[113,117,118]$. Water temperature can be lowered by properly adjusting the thermostat on the water heater or by using an anti-scald device at the tap $[14,112,119,120]$. Regarding hot water temperature, a study performed by Runyan et al. revealed that only one-fourth of respondents indicated that they knew the temperature of the thermostat setting of their hot water heaters. About 9\% indicated they knew the temperature of their hot water at the tap. Only $6 \%$ reported the presence of an anti-scald device in their homes [102]. Burns are a frequent known risk during kitchen activities. Yared et al. $[107,108]$ showed that burns during cooking activities are burns due to a splash of a hot liquid and burns by contact with a hot object.

Cognitive changes may interfere with the ability of elderly people to react to the dangers of a fire or burn. Factors such as limited mobility, dementia, medications, smoking and aging itself may increase the vulnerability to burn risk. Additionally, the low financial income of elderly people can be considered a reason for not having advanced warning devices such as a smoke and/or carbon monoxide (CO) alarms [121] and they may not be able to support home maintenance and improvement expenses which may reduce the risk of a fire or burn injury according to the U.S. Fire Administration/National Fire Data Center [109], since safety may not rank high on the list of concerns for people with a low income. A study performed by Bishai et al. [122] revealed that during a safety inspection, more than $50 \%$ of elderly people had inadequate safety equipment in their bathroom and over $30 \%$ had tap water temperatures exceeding $140^{\circ} \mathrm{F}\left(60^{\circ} \mathrm{C}\right)$, which may lead to a scald injury. Furthermore, households with low income are less likely to have a safe heating system, safe electrical services, and fire safety measures.

\subsubsection{Risk of Intoxication by Gas/Smoke}

Extensive investigations of human fire fatalities with respect to exposure to toxic atmospheres have shown carbon monoxide (CO) to be the primary toxicant. Although $\mathrm{CO}$ is not the most toxic gas at low concentrations, it is always one of the most abundant toxic gases produced by fires. Fire usually produces carbon dioxide, $\mathrm{CO}_{2}$, in large quantities. Although it is not particularly toxic, it displaces oxygen $\left(\mathrm{O}_{2}\right)$ and thereby causes the rate and depth of breathing to increase. This often causes an accelerated inhalation of other toxicants and irritants [100]. Heating equipment and kitchen appliances may cause carbon monoxide poisoning, in addition to being associated with residential fires [123-125]. When a carbon-based fuel (e.g., gas, oil, kerosene, propane, wood, or charcoal) is burned, then carbon monoxide is released. The emission of carbon monoxide may reach a dangerous level in situations where an appliance is not working properly or the ventilation is not enough [123-128].

Each year in the United States, there are more than 200 residential carbon monoxide poisoning deaths, two-thirds of which are related to heating equipment [102,123]. A study performed by Meredith et al. [129] revealed that although the number of death cases caused by carbon monoxide poisoning has been reduced since natural gas was substituted for coal gas, a considerable number of victims still exist because of CO poisoning. About 1000 people die annually in England and Wales and most of them do not reach the hospital alive. The study of Meredith et al. shows that there are several common indoor sources of $\mathrm{CO}$ gas, such as improperly maintained and ventilated heating systems [130], smoke from all types of fires, and household gas. Inhalation of methylene chloride (e.g., paint strippers) may also lead to carbon monoxide poisoning [131]. Elderly people are at a risk of intoxication which can result from cigarette smoke, because smoke contains about $4 \%$ carbon monoxide [132].

\subsubsection{Ambient Assistive Technology for Fire Risk}

To achieve fire safety, preventing fire ignition and managing fire impacts is required [100]. Therefore, fire-detecting devices must be able to detect the fire before untenable conditions develop. 
Detection devices can be categorized according to the fire signature that the device senses. The fire signature is an identifiable change in the local environment caused by a fire. Examples of fire signatures are the appearance of specific amounts and types of aerosols, the presence of converted and radiated heat, and the appearance of gases evolved by a fire. Detection systems are designed to identify one or more of these changes in the environment [100]. Some primitive and simple safety measures and recommendations to assist elderly people against fire risk at home exist, such as fire and smoke alarms, a fire extinguisher and an escape plan for the household. Runyan et al. [102] revealed that taking into consideration some safety measures and practices could prevent injuries and possibly deaths due to fire at home by installing smoke alarms on each level of a home, and such alarms must be properly maintained $[102,133,134]$. The Centers for Disease Control and Prevention (CDC) recommend changing the batteries in battery-operated smoke alarms annually. They also recommend testing smoke alarms monthly to ensure that they are working properly [135]. In addition, there are suggested fire safety recommendations such as keeping a fire extinguisher in the kitchen for small fires $[113,135]$ and having a fire escape plan for the household.

Ambient assistive technology for fire due to cooking activities. We review assistive technology for fire risk detection and prevention. At first, we review existing systems to protect elderly people against cooking risks; then we review algorithms and techniques for fire detection.

Few electrical cooking devices equipped with limited safety features are available on the market. For example, the Electrolux INSPIRO oven contains programmable cooking modes. According to the selected cooking mode, the oven calculates the cooking time and temperature. Other companies commercialize ovens with a tactile screen and a network connection to be remotely controlled. Numerous manufacturers integrate Light Emitting Diodes (LEDs) to indicate that an oven surface is hot to prevent burns. However, the concentration of elderly people is mainly on the cooking task itself and she/he may not notice the lit LED. Generally speaking, safety measures are partially considered in the existing commercial cooking devices. StoveGuard, SafeCook and HomeSensor propose a timer system to switch off an oven if there is no attendance after a certain programmed time. Still, risks may occur within this period of time.

The basic existing solution to handle fire risk at home is installing fire alarms, as we discussed earlier. The main concern of fire alarms is to detect the occurrence of fire quickly, so fire rescue agents can intervene in time. However, existing fire alarms have several drawbacks, particularly for elderly people. These people usually forget to replace alarm batteries regularly. In addition, fire alarms generate false alarms (e.g., in the presence of a small quantity of smoke generated by regular cooking). This situation disturbs elderly people, which increases their tendency to uninstall fire alarms at their homes. Lushaka et al. established an elaborate system that relies on existing smoke alarms to detect a potential fire risk, and consequently reacts by switching off the oven power supply [106]. The system considers only a fire risk and depends on existing smoke alarms. Doman et al. established a system for assisting elderly people in the kitchen through video and audio [136]. This system reminds the user to follow the correct steps when performing a cooking task, so they can possibly avoid cooking hazards, but it does not react when a dangerous situation occurs. Other intelligent assistive technologies are designed for people with cognitive deficiencies. Li et al. proposed a design for a smart kitchen environment to assist elderly people suffering from dementia in the cooking process. Using the system, caregivers remotely instruct users according to a cooking workflow. In addition, a visual surveillance system with multiple cameras enables a watcher to observe cooking conditions and track user activities and object movement [137]. This system is not completely automatic, since it requires observer intervention and it is based on visual monitoring by cameras, which may be considered intrusive. Sanchez et al. established a system that assists people in the kitchen and reacts when a potentially dangerous situation is detected [138]. The system detects rapid variations in temperature and smoke in the kitchen, and sends a notification (with camera shots) to the fire department and caregivers. In addition, the system activates exhaust fans and a fire extinguishing suppression system. A number of studies mention oven monitoring as a part of larger systems to track activities of daily 
living. Alwan et al. [139] measured oven usage and Wai et al. [140] proposed detecting unsafe usage of the oven. Both systems use embedded temperature sensors to measure the burner status, ultrasonic sensors to detect the presence of a pot and electric current sensors to detect oven usage and levels of abnormality in the kitchen. The previous systems either require modifications to the oven to install the sensors, or use visible-light cameras. Visible-light cameras are usually considered intrusive and are sensitive to cooking smoke. Yuan et al. developed an automated top oven monitoring system based on a thermal camera to detect dangerous situations [141]. The system alerts the user or caregiver when a dangerous situation occurs. The system does not require modifications to the oven, so it fits any existing oven and respects user privacy, because it is based on thermal imaging instead of a visible-light camera. Since the thermal camera does not process regular images, user privacy is preserved. However, the thermal camera has significant limitations since it is sensitive to cooking heat and smoke.

Algorithms and techniques for fire risk detection. Traditional fire detection technology usually uses a single-unit fire detector. The single-unit fire detector predicts a fire by detecting only one parameter of the fire spot. It is clear that a single parameter is inadequate to respond to the diverse fire characteristics with equal sensitivity. For example, a temperature detector is only sensitive to the flaming fire, not to smoldering fire, and it also cannot distinguish the heat produced by a fire from that produced from air-conditioning or from cooking steam. Another example is the photoelectric smoke detector, which is a sensor with satisfactory performance that detects either flaming fire or smoldering fire. The photoelectric smoke detector shows different levels of sensitivity to different fire types. It is generally more sensitive to the gray smoke emitted by smoldering fires, and less sensitive to the black smoke emitted by flaming fires [142]. In addition, there is no type of single-unit fire detector that can detect all kinds of fire efficiently [143].

Multi-sensor data fusion detection technology may overcome the limitations of the single-unit fire detectors. Intelligent techniques and methods are used to fuse the data obtained by diverse sensors that lead to determining the fire probability. Therefore, predicting fire risk can be improved [143]. Research studies discuss the possibility of detecting fire situations by monitoring the following gases in cooking smoke: carbon monoxide $(\mathrm{CO})$, carbon dioxide $\left(\mathrm{CO}_{2}\right)$, or volatile organic compounds (VOC). Monitoring these gases could enable detecting a fire situation at an early stage [143-147]. Bashyal et al. [148] and Charumporn et al. [149] proved that it is possible to classify fire situations according to their triggering reasons by monitoring the following parameters: VOC, humidity, and ambient temperature. They classify fire accidents according to their origins, based on data from sensors deployed in 12 fire situations, and design a fire detection algorithm based on neural networks. Milke et al. [146] worked on fire detection using 87 examples of fire situations. In another study, Johnson [145] used 42 examples of normal and abnormal cooking situations. He observed that the boundary between normal and abnormal cooking situations corresponds to a threshold of the output voltage of the gas sensors, and hence designed rule-based algorithms for fire detection. Chen et al. [143] proposed an algorithm for fire detection based on sensory information from a database. In their fire detection system, the fire experiential characteristic and the fire data-fitting characteristic of the fire signal data are fused by a fuzzy inference system to get the fire probability. Concretely, the system of Chen et al. employs a three-layer data fusion structure, in which the surrounding temperature, smoke density and CO density are considered as the most important fire-detecting signals. The fire experience characteristic and the data-fitting characteristic are respectively extracted by the expert database and neural network. These two characteristics are fused by a fuzzy inference system to get the last fire probability. As a result of integrating multi-sensor signals and fusing them intelligently, this system eliminates false warnings or delay warnings caused by the single sensor. It also improves the accuracy for predicting the fire probability [143].

There are also approaches based on artificial intelligence techniques to distinguish abnormal activity in the kitchen. As an example, Yin et al. [54] proposed abnormal human activity recognition. Several studies mention oven monitoring as a part of larger systems to track activities of daily living. 
Wai et al. [140] propose a sensor-based system to detect unsafe usage of the oven, and discriminate certain levels of abnormality in certain simple kitchen activities based on fuzzy logic. The discussed system requires modifications to the oven to install the sensors, and detects certain hazardous situations in the kitchen. However, abnormal activity situation detection does not always guarantee identifying a fire risk in the context of cooking safety in the kitchen.

Yared et al. $[107,108]$ established a preventive approach for enhancing the safety of elderly people with a smart oven cooking-safe system that proactively reacts to hazards in order to prevent cooking-associated risks (fire, burn by a splash, burn by contact with a hot object, and intoxication by gas/smoke). The context-aware cooking-safe system is composed of sensor nodes that enable collecting contextual data around the oven. The context is processed to prevent risks, based on the results of their insightful experimental cooking risk analysis [150]. Based on the gathered context, the system monitors and measures the pertinent parameters around the oven. The cooking-safe system is provided with a fuzzy logic-based reasoning engine that manages the detection of risk situations and determines their severity levels according to the contextual information around the oven [151]. Table 4 summarizes the assistive technology for fire risk.

Table 4. Ambient assistive technology for fire risk.

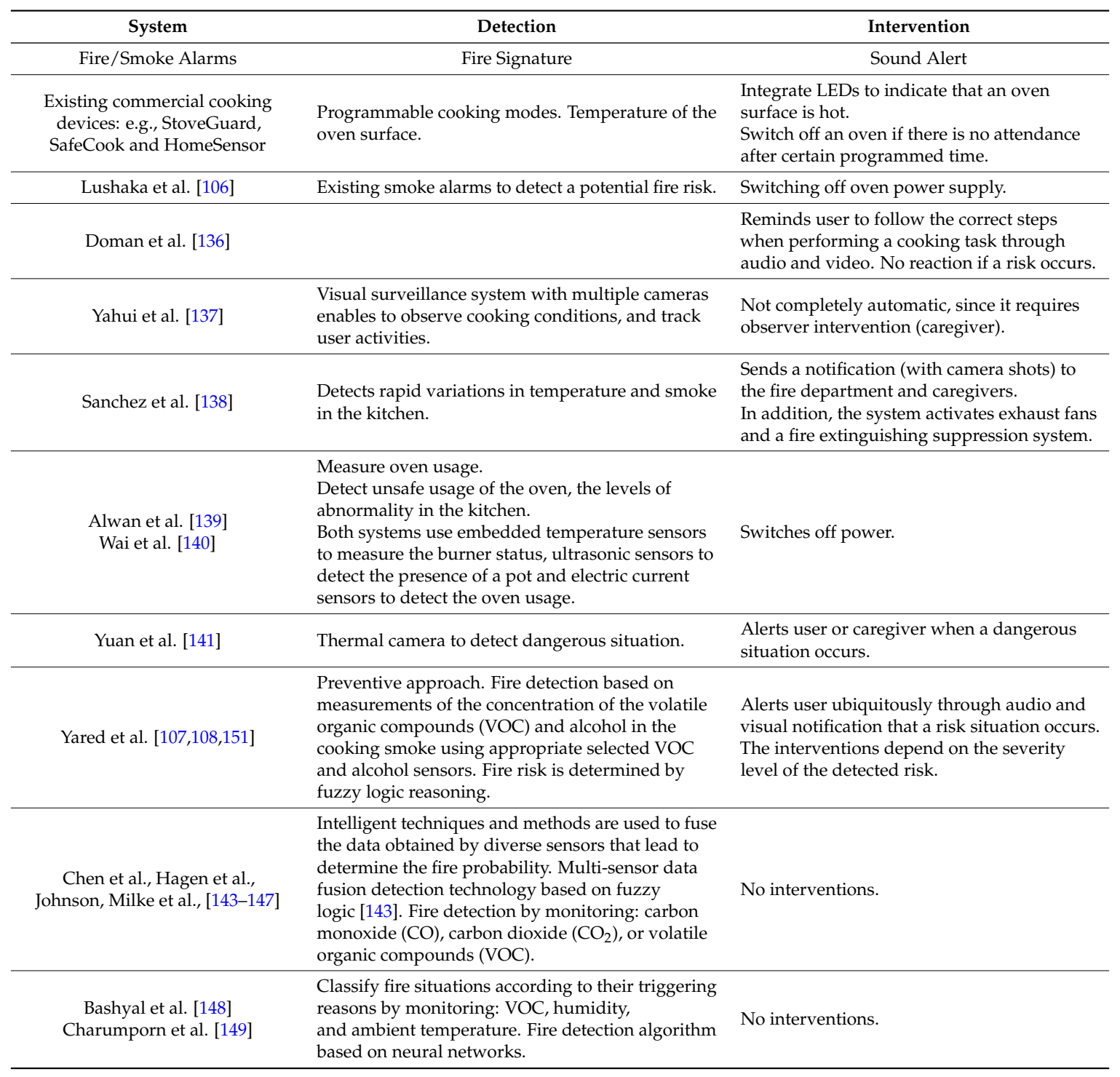




\subsubsection{Ambient Assistive Technology for Burn Risk}

A burn is a significant source of risk for elderly people at home. In order to assist elderly people against burn risk, specialized fire/burn prevention organizations recommend installing an interconnected grid of working smoke and $\mathrm{CO}$ alarms combined with ionization and photoelectric smoke alarms in each room and level of the house, along with regularly checking the alarm status. In addition, elderly people are recommended to keep adjusting and fixing hot water to a safe temperature while taking a shower or using hot water at home. For burns related to cooking activities, Virtual Flame [152] is a technology that involves the installation of LEDs around the oven burner. Depending on the desired cooking power, these LEDs will project their light around the edge of the utensil in the form of sparks. As more cooking power is more intense, the sparks will be larger. This solution enables easy understanding of what is potentially a hot utensil, indicating to the user of the oven to handle it with care to avoid the risk of burns. There are also commercial devices to prevent burn risk such as anti-scald valves for the shower head or tub faucet. These valves stop or interrupt the flow of water when the temperature reaches a certain threshold to prevent hot water from coming out of the tap. These valves will not allow the faucet to become fully operational until the water temperature is reduced to a safe temperature. Other recommendations can be summarized by opening the cold water first, then gradually adding hot water, and for elderly people with limited mobility, these include a shower chair, grab bars and a notification device to call when there is an emergency. For elderly people who have thin skin, they must avoid fluctuations in water temperature when taking a shower [120].

Yared et al. $[107,108,151]$ established a preventive approach to assist elderly people against burn risk during cooking activities. Yared et al. identified burn risk due to the splash of hot liquids and contact with hot objects. Their cooking-safe system detects the burn risk by monitoring the relative humidity (its variation is an important indicator of a liquid temperature in a utensil), utensil temperature, burner temperature, and presence of an object on an oven burner. The severity of the burn risk is determined due to a fuzzy logic-based reasoning engine.

\subsubsection{Ambient Assistive Technology for Intoxication by Gas/Smoke Risk}

The simplest assistive technology to protect the elderly against the gas/smoke intoxication risk is to install carbon monoxide detectors in order to prevent carbon monoxide poisoning $[125,153,154]$. Several studies suggest that homes with carbon monoxide detectors may be less affected by carbon monoxide poisoning [155-157].

Installing $\mathrm{CO}$ alarms is recommended to detect $\mathrm{CO}$ and they notify its presence before the levels become life-threatening. When alarms sound, people are required to immediately leave the place and to call the emergency line. Since CO gas cannot be detected by humans, it is recommended that house inhabitants check for symptoms of $\mathrm{CO}$ poisoning (e.g., headache, fatigue) which may indicate a $\mathrm{CO}$ leakage [111].

Intoxication by gas constitutes a frequent known risk during cooking activities. Jain et al. [158] proposed a gas detection system based on a wireless gas sensor network (WGSN). The system detects the proportion of gas in the kitchen and can predict a situation of gas intoxication.

A review performed by Harper et al. [159] suggests some recommendations for elderly people to prevent gas poisoning, such as regular servicing of gas appliances and ensuring adequate ventilation. They also recommend providing houses with carbon monoxide testers with both visual and audible alarms. The detectors vary in their sensitivity to carbon monoxide, with some only adequate to detect relatively high levels of ambient carbon monoxide, which would not protect against low-level poisoning.

Yared et al. $[107,108]$ established a preventive approach to assist elderly people against the risk of intoxication by $\mathrm{CO}$ during cooking activities. Their cooking-safe system monitors the $\mathrm{CO}$ gas concentration in the cooking smoke due to a $\mathrm{CO}$ sensor and the severity of the intoxication risk is determined by a fuzzy logic-based reasoning engine [151]. 


\subsubsection{Discussion}

We reviewed existing ambient assistive technology for elderly people to enhance their safety facing risks of fire, burns and intoxication by $\mathrm{CO}$, particularly during cooking activities. Traditional fire/smoke alarm systems suffer from two major drawbacks: they give false alarms and they require regular replacement of batteries. These two drawbacks make the usage of fire/smoke alarms inconvenient for elderly people. More elaborate systems are designed to assist elderly people during cooking. These systems are either based on a visible-light camera or require modifications to the oven which limits their practical usage. Sensor-based systems need to satisfy certain requirements in order to be practically accepted by elderly people. These requirements are: (1) flexibility, such that adding new sensors or removing sensors if required will be possible and easily performed; (2) simple physical installation, such that the sensors can be placed in alternative locations if required; (3) non-intrusiveness, such that the components of the system are placed in adequate positions to monitor hazards and detect risk situations such that the system does not disturb elderly people's movements in the kitchen. It is also important to take into consideration the needs and the requirements of elderly people before designing an assistive technology system and to perform evaluation studies for the acceptability of the system by elderly people.

\subsection{Risk of Inactivity and the Assistive Technology}

Physical and social activities are very important for elderly people as they promote healthy aging. Aging is a process associated with cognitive and physiological decline, which causes activity limitations and participation restrictions [160]. Elderly people become less active and more prone to social isolation and loneliness, which complicates their health situation and causes premature mortality [161]. Participation in social and physical activities, however, results in a lower risk of cognitive decline (e.g., dementia) [162] and improves the well-being of elderly people [163]. Physical activity slows down the progression of diseases, and it is in general a promoter of health [164]. Increasing participation in social activities improves cognitive abilities for elderly people [165] and consequently leads to a higher quality of life [166].

A research work studied the impact of physical inactivity on worldwide health levels. It was found that by decreasing physical inactivity by $10 \%$ to $25 \%$, between 533,000 and 1.3 million deaths could be prevented per year. Additionally, the worldwide life expectancy would rise by approximately 0.68 years $[167,168]$.

Assistive technologies that assist in promoting physical and social activities for elderly people have been explored and applied in a limited way in research works; however, interest and work in this area is growing, particularly in the areas of gamification and mobile applications $[167,169,170]$. Barua et al. [171] attempted to measure sedentary behavior and prompt a user to stand after long periods of inactivity. Virtual reality has been experimented as an innovative technique for promoting physical activity in unsupervised physiotherapy rehabilitation environments [170]; however, few research works have been established regarding the ability for virtual reality interventions to influence physical activity levels [172]. Virtual reality applications usually require wearable sensors including smartphone sensors. Wearable sensors have a strong presence in health, fitness and well-being technology, with products (e.g., Apple Health, Google Fit, and Apple Watch) and systems that track various body measurements including steps, sleep, heart rate, burned calories, distance traveled and individual exercises. Physical activity trackers have software that allows users to set physical activity goals and prompts them to work towards these goals [173].

Persuasive technology for promoting physical and social activities in elderly people can be categorized as follows. We cite representative examples for each category.

- Video games

In order to promote healthy aging, several applications are designed to support elderly people in leading a healthy lifestyle. Applications in this category incorporate gaming technology to provide 
motivations for improving health. The reasons for using games to motivate physical activity for elderly people are [174]: (a) sending the counted steps with optional comments to friends and/or family members or other selected people; (b) checking the progress of their friends and to what extent they achieve their goals; (c) checking the curves of progress of the last week; (d) sending messages to their friends; and (e) sending a challenge request to their friends concerning the number of steps. A representative example of video games is PiNiZoRo [175] where its goal is to motivate elderly people to move out to continue playing. Players can collect items only if they go to certain geographic areas.

- $\quad$ Exergaming

It means exercise and gaming. The idea is to exercise while playing games in order to enjoy sports. A representative example of this category is "social exergames to persuade seniors to increase physical activity" [176].

\section{- Motivation}

"Flowie" [177] is a virtual coach, in the shape of an animated flower, used to motivate elderly people to walk more in order to reach a walking goal. "QueFaire" is a mobile-based activity-promoting system to improve the well-being of elderly people by recommending the most likeable activities for an elderly person according to his/her profile/preferences [178]. "Playful" is another existing activity-promoting system that offers a solution to increase physical and social activities. The system is designed for elderly people living in a care facility. Elderly people who live independently can use this system as well. Playful enables the registration of the most common activities performed and preferred by elderly people, which helps caregivers to plan physical and social activities for a week. Each resident receives a list of planned activities via a weekly newspaper. The list is also displayed in different locations of the care facility. A light next to each display is switched on for a short time to remind elderly people of a coming activity [179].

- Communication between people (virtual or real)

An example of virtual communication is the "virtual imaginary interlocutor" [180]. The idea is to talk to an interlocutor because even an imaginary interlocutor can help people mentally and improve their well-being. For this, a tablet or a smartphone is used to not "stay alone". The virtual interlocutor is an avatar which allows the reduction of the stress of the user.

An example of a real interlocutor is "promoting intergenerational communication through location-based asynchronous video communication" [181]. The idea is to exchange history, because many people like to share their past, present, and imagination. This application also enables the user to choose a location on the map to share a history. The main goal is to motivate elderly people and their families to create a new mobile media. This technique keeps elderly people at home because researchers found that elderly people stay at home with special schedules to interact with their children. This method is good to get children to contact their grandparents more often.

Another example, MELCO (MELCO project (mobile elderly living community) [182]) is an ICT system that targets elderly people and tries to increase their social activities and monitor their health at the same time. The system enables the user to build a virtual social network among people, their families, and friends. Co-living [183] aims to build an "ICT-based virtual collaborative social living community for aging people" which promotes active living and independence. The system is used in an extended care facility for elderly people. It is composed of a virtual social network and a client application on a tablet. Activities are promoted through this social network.

Table 5 summarizes the existing technology systems to promote physical and social activities to assist elderly people against inactivity risk. 
Table 5. Categorization of persuasive technology for inactivity risk.

\begin{tabular}{cr}
\hline & Physical/Social Activities Promoting Representative Examples \\
\hline Video games & PiNiZoRo [175] \\
\hline Exergaming & Social exergames to persuade seniors to increase physical activity [176] \\
\hline Motivation & QueFaire [178], Flowie [177], Playful [179] \\
\hline $\begin{array}{c}\text { Communication between } \\
\text { people (virtual or real) }\end{array}$ & $\begin{array}{c}\text { Virtual imaginary interlocutor [180] } \\
\text { Promoting Intergenerational communication through } \\
\text { location-based asynchronous video communication [181] }\end{array}$ \\
\hline
\end{tabular}

\section{Discussion}

Social media has changed the way people interact with each other in the last decade. Web, e-mail, and social media networks (such as Facebook and Twitter) have changed the way younger people are communicating with each other. Moreover, many government services are now offered on the Internet. Many people are taking advantage of these online services, which are faster and more accessible. Different communities are increasing their public participation using social media [184]. According to Buettner et al. and Cohen-Mansfield et al. [185,186], there are many benefits for elderly people to use technology, including psychological benefits (such as an increase in independence, self-respect, and acceptance in the society) and fiscal benefits (relieving the personal care cost). On the other hand, there are several ICT initiatives trying to promote healthier and more active lifestyles. Nevertheless, studies show that people over 65 years of age are excluded from this digital revolution [187]. The literature review also reveals that most of the ICT systems are designed for younger generations. Adapting solutions to elderly people and their needs is a fact that needs to be addressed. We believe that context-awareness tools can help build solutions that are more adaptive to elderly people.

\section{Conclusions and Future Directions}

In this paper, we reviewed the major indoor risks that are addressed by assistive technology for elderly people during their indoor ADL. We have presented interesting representative examples of the recent assistive technology related to major indoor risks for elderly people: falls, wrong self-medication management, fire, burn, intoxication by gas/smoke, and inactivity. We identified also other risks such as abuse and psychological related risks (e.g., loneliness, stress, depression); however, abuse and psychological related risks are rarely addressed by assistive technology. We also classified the techniques and algorithms for automatic detection of risks by ambient assistive technology systems and the basic components and interventions of the assistive technology to help elderly people and enhance their safety.

A general framework for assistive technology systems can be described as follows: (1) a monitoring and sensing module composed of wearable and ambient sensors and devices according to the risk type; (2) an automatic detection module (reasoning engine) that receives sensory data and processes it to detect a risk situation based on either fixed/adaptive thresholds or based on artificial intelligence techniques (e.g., machine learning, fuzzy logic, and neural networks), or based on activity recognition algorithms/techniques; (3) an intervention module that is responsible for triggering appropriate actions to assist elderly people in risk situations. Generally speaking, the interventions are notifying caregivers or family members in case of a fall, a medication non-adherence, or a fire risk situation (in addition to switching off the power source in case of a fire risk). For the inactivity risk, assistive technology can be generally viewed as persuasive technology to motivate elderly people to exercise and take part in physical/social activities. In addition, some assistive technology for the inactivity risk monitors elderly people to estimate their inactivity level using several monitoring techniques and then processing the sensory data to infer an inactivity risk. The intervention could be promoting physical and social activities. 
Assistive technology promises to reduce caregiving costs for elderly people; however, there are still a few challenges that are difficult to overcome. Barriers to technology usage by elderly people include age-related obstacles, challenging features of the technology (some of which can be overcome by an adaptable design), and social factors that are more difficult to quickly modify. Technological innovations are required regarding the design considerations for an aging population and activating the social network around elderly people. This leads to enhanced quality of life for elderly people and improves their independent living.

Many elderly people deal with technology through assistive technology [188]. Some factors that caused elderly people to abandon assistive technology are a need for social interaction and a lack of trust in the technologies [189]. A successful example of technology adoption is smartphone technology. A comprehensive literature review determined that contextual, sociological, techno-economic, psychological, personal and Aging-specific factors contributed towards the acceptance of smart phones [190]. Therefore, designers and developers of assistive technology systems have to draw high attention to elderly people's requirements and needs in order to accept the assistive technology systems.

As future directions, we intend to provide a platform that integrates several systems for providing elderly people with an assistive platform that they can rely on for indoor and outdoor daily activities. This can enhance their feeling of safety and security, and thus enables elderly people to go about their activities independently and will consequently improve the quality of their life.

Conflicts of Interest: The authors declare no conflict of interest.

\section{References}

1. Zoncu, R.; Efeyan, A.; Sabatini, M. mTOR: From growth signal integration to cancer, diabetes and ageing. Nat. Rev. Mol. Cell Biol. 2011, 12, 21-35. [CrossRef] [PubMed]

2. Mynatt, D.; Rogers, A. Understanding User Needs and Attitudes. Gesture 2004, 3, 36-41.

3. Billette, J.; Janz, T. Living Arrangements of Seniors; Canadian Census: Ottawa, ON, Canada, 2011. Available online: http://www12.statcan.gc.ca/census-recensement/2011/as-sa/98-312-x/98-312x2011003_4-eng.pdf (accessed on 8 October 2016).

4. Martel, L.; Menard, F. Statistics Canada; Canadian Census, Demography Division: Ottawa, ON, Canada, 2011. Available online: http://www12.statcan.gc.ca/census-recensement/2011/as-sa/98-311-x/98-311-x2011001eng.pdf (accessed on 8 October 2016).

5. Toshio, O.; Iwasaki, N. Innovative applications and strategy on ICT applications for aging society: Case study of Japan for silver ICT innovations. In Proceedings of the 7th ACM International Conference on Theory and Practice of Electronic Governance, Seoul, Korea, 22-25 October 2013.

6. Loraine, A.; Cole, S.; Goodkind, D.; He, W. 65+ in the United States; U.S. Census Bureau, Government Printing Office: Washington, DC, USA, 2014.

7. Jacobsen, A.; Kent, M.; Lee, M.; Mather, M. America's Aging Population. Popul. Bull. 2011, 66, 1-20.

8. Robinovitch, S.; Brumer, R.; Maurer, J. Effect of the squat protective response on impact velocity during backward falls. J. Biomech. 2004, 37, 1329-1337. [CrossRef] [PubMed]

9. Khan, S.; Hoey, J. Review of Fall Detection Techniques: A Data Availability Perspective. 2016, arXiv:1605.09351.

10. World Health Organization. WHO Global Report on Falls Prevention in Older Age. Available online: http://www.who.int/violence_injury_prevention/publications/other_injury/falls_prevention (accessed on 22 July 2016).

11. Rubenstein, L.; Josephson, K.; Robbins, A. Falls in the nursing home. Ann. Intern. Med. 1994, 121, $442-451$. [CrossRef] [PubMed]

12. Important Facts about Falls. Available online: http://www.cdc.gov/HomeandRecreationalSafety/Falls / adultfalls.html (accessed on 23 July 2016).

13. Seniors' Falls in Canada: Second Report. Public Health Agency of Canada, 2014. Available online: http:/ / www.phac-aspc.gc.ca/seniors-aines/publications/public/injury-blessure/seniors_falls-chutes_ aines/index-eng.php (accessed on 8 October 2016). 
14. Injury Prevention \& Control: Data \& Statistics (WISQARS ${ }^{\mathrm{TM}}$ ). Available online: http://www.cdc.gov/ injury/wisqars/fatal_injury_reports.html (accessed on 27 July 2016).

15. Alexander, H.; Rivara, P.; Wolf, E. The cost and frequency of hospitalization for fall-related injuries in older adults. Am. J. Public Health 1992, 82, 1020-1023. [CrossRef] [PubMed]

16. Sterling, A.; O'Connor, A.; Bonadies, J. Geriatric falls: Injury severity is high and disproportionate to mechanism. J. Trauma Acute Care Surg. 2001, 50, 116-119. [CrossRef]

17. Parkkari, J.; Kannus, P.; Palvanen, M.; Natri, A.; Vainio, J.; Aho, H.; Vuori, I.; Järvinen, M. Majority of hip fractures occur as a result of a fall and impact on the greater trochanter of the femur: A prospective controlled hip fracture study with 206 consecutive patients. Calcif. Tissue Int. 1999, 65, 183-187. [CrossRef] [PubMed]

18. Hayes, C.; Myers, R.; Morris, N.; Gerhart, N.; Yett, S.; Lipsitz, A. Impact near the hip dominates fracture risk in elderly nursing home residents who fall. Calcif. Tissue Int. 1993, 52, 192-198. [CrossRef] [PubMed]

19. Jager, E.; Weiss, B.; Coben, H.; Pepe, E. Traumatic brain injuries evaluated in U.S. emergency departments, 1992-1994. Acad. Emerg. Med. 2000, 7, 134-140. [CrossRef] [PubMed]

20. Stevens, A.; Corso, S.; Finkelstein, A.; Miller, R. The costs of fatal and nonfatal falls among older adults. Injury Prev. 2006, 12, 290-295. [CrossRef] [PubMed]

21. Vellas, J.; Wayne, J.; Romero, J.; Baumgartner, N.; Garry, J. Fear of falling and restriction of mobility in elderly fallers. Age Ageing 1997, 26, 189-193. [CrossRef] [PubMed]

22. Gillespie, D.; Robertson, C.; Gillespie, J.; Sherrington, C.; Gates, S.; Clemson, M.; Lamb, E. Interventions for preventing falls in older people living in the community. Cochrane Database Syst. Rev. 2009, 2. [CrossRef]

23. Chaudhuri, S.; Thompson, H.; Demiris, G. Fall detection devices and their use with older adults: A systematic review. J. Geriatr. Phys. Ther. 2014, 37, 178-196. [CrossRef] [PubMed]

24. Porter, E.J. Wearing and using personal emergency response system buttons. J. Gerontol. Nurs. 2005, 31, 26-33. [CrossRef] [PubMed]

25. Fleming, J.; Brayne, C. Inability to get up after falling, subsequent time on floor, and summoning help: Prospective cohort study in people over 90. BMJ 2008, 337. [CrossRef] [PubMed]

26. Bourke, K.; O'Brien, V.; Lyons, M. Evaluation of a threshold-based tri-axial accelerometer fall detection algorithm. Gait Posture 2007, 26, 194-199. [CrossRef] [PubMed]

27. Bourke, K.; van de Ven, W.; Chaya, E.; OLaighin, M.; Nelson, J. Testing of a long-term fall detection system incorporated into a custom vest for the elderly. In Proceedings of the IEEE Engineering in Medicine and Biology Society, Vancouver, BC, Canada, 20-25 August 2008; pp. 2844-2847.

28. Kangas, M.; Vikman, I.; Wiklander, J.; Lindgren, P.; Nyberg, L.; Jämsä, T. Sensitivity and specificity of fall detection in people aged 40 years and over. Gait Posture 2009, 29, 571-574. [CrossRef] [PubMed]

29. Bourke, K.; van de Ven, P.; Gamble, M.; O'Connor, R.; Murphy, K.; Bogan, E.; McQuade, E.; Finucane, P.; Olaighin, G.; Nelson, J. Assessment of waist-worn tri-axial accelerometer based fall-detection algorithms using continuous unsupervised activities. In Proceedings of the IEEE Engineering in Medicine and Biology Society, Buenos Aires, Argentina, 1-4 September 2010.

30. Bloch, F.; Gautier, V.; Noury, N.; Lundy, E.; Poujaud, J.; Claessens, E.; Rigaud, S. Evaluation under real-life conditions of a stand-alone fall detector for the elderly subjects. Ann. Phys. Rehabil. Med. 2011, 54, 391-398. [CrossRef] [PubMed]

31. Igual, R.; Medrano, C.; Plaza, I. Challenges, issues and trends in fall detection systems. BiolMed. Eng. Online 2013, 12. [CrossRef] [PubMed]

32. Belshaw, M.; Taati, B.; Giesbercht, D.; Mihailidis, A. Intelligent Vision-Based Fall Detection System: Preliminary Results from a Real World Deployment. In Proceedings of the RESNA/ICTA 2011: Advancing Rehabilitation Technologies for an Aging Society, Toronto, ON, Canada, 5-8 June 2011.

33. Belshaw, M.; Taati, B.; Snoek, J.; Mihailidis, A. Towards a single sensor passive solution for automated fall detection. In Proceedings of the IEEE Engineering in Medicine and Biology Society, Boston, MA, USA, 30 August-3 September 2011; pp. 1773-1776.

34. Sixsmith, A.; Johnson, N. A smart sensor to detect the falls of the elderly. IEEE Pervasive Comput. 2004, 3, 42-47. [CrossRef]

35. Li, Y.; Zeng, Z.; Popescu, M.; Ho, K.C. Acoustic fall detection using a circular microphone array. In Proceedings of the IEEE Engineering in Medicine and Biology Society, Buenos Aires, Argentina, 31 August-4 September 2010. 
36. Popescu, M.; Li, Y.; Skubic, M.; Rantz, M. An acoustic fall detector system that uses sound height information to reduce the false alarm rate. In Proceedings of the IEEE Engineering in Medicine and Biology Society, Vancouver, BC, Canada, 20-25 August 2008.

37. Alwan, M.; Rajendran, P.J.; Kell, S.; Mack, D.; Dalal, S.; Wolfe, M.; Felder, R. A Smart and Passive Floor-Vibration Based Fall Detector for Elderly. In Proceedings of the 2nd International Conference on Information \& Communication Technologies: From Theory to Applications (ICTTA), Omayyad Palace Damascus, Syria, 24-28 April 2006.

38. Yu, X. Approaches and principles of fall detection for elderly and patient. In Proceedings of the IEEE 10th International Conference on e-Health Networking Applications and Services (HealthCom'08), Singapore, 7-9 July 2008; pp. 42-47.

39. Habib, M.A.; Mohktar, M.S.; Kamaruzzaman, S.B.; Lim, K.S.; Pin, T.M.; Ibrahim, F. Smartphone-based solutions for fall detection and prevention: Challenges and open issues. Sensors 2014, 14, 7181-7208. [CrossRef] [PubMed]

40. Lee, K.; Robinovitch, S.; Park, E. Inertial sensing-based pre-impact detection of falls involving near-fall scenarios. IEEE Trans. Neural Syst. Rehabil. Eng. 2015, 23, 258-266. [CrossRef] [PubMed]

41. Bourke, A.; Lyons, G. A threshold-based fall-detection algorithm using a bi-axial gyroscope sensor. Med. Eng. Phys. 2008, 30, 84-90. [CrossRef] [PubMed]

42. Chen, J.; Kwong, K.; Chang, D.; Luk, J.; Bajcsy, R. Wearable sensors for reliable fall detection. In Proceedings of the 27th Annual International Conference in EMBS, Shanghai, China, 1-4 September 2005.

43. Li, Q.; Stankovic, J.; Hanson, M.; Barth, A.; Lach, J.; Zhou, G. Accurate fast fall detection using gyroscopes and accelerometer-derived posture information. In Proceedings of the 2009 Sixth International Workshop on Wearable and Implantable Body Sensor Networks, Berkeley, CA, USA, 3-5 June 2009; pp. 138-143.

44. Sposaro, F.; Tyson, G. iFall: An Android application for fall monitoring and response. In Proceedings of the Annual International Conference of the IEEE on Engineering in Medicine and Biology Society (EMBC), Minneapolis, MN, USA, 3-6 September 2009.

45. Lopes, I.C.; Vaidya, B.; Rodrigues, J. SensorFall—An accelerometer based mobile application. In Proceedings of the 2nd International Conference on Computational Science and Its Applications, Jeju, Korea, 10-12 December 2009.

46. Perry, J.; Kellog, S.; Vaidya, S.; Youn, J.-H.; Ali, H.; Sharif, H. Survey and evaluation of real-time fall detection approaches. In Proceedings of the 6th International Symposium on High-Capacity Optical Networks and Enabling Technologies (HONET), Alexandria, Egypt, 28-30 December 2009.

47. Bourke, K.; O’Donovan, J.; OLaighin, M. Distinguishing falls from normal ADL using vertical velocity profiles. In Proceedings of the IEEE Engineering in Medicine and Biology Society, Lyon, France, 23-26 August 2007.

48. Bourke, K.; O'Donovan, J.; Olaighin, M. The identification of vertical velocity profiles using an inertial sensor to investigate pre-impact detection of falls. Med. Eng. Phys. 2008, 30, 937-946. [CrossRef] [PubMed]

49. Zhang, T.; Wang, J.; Xu, L.; Liu, P. Fall detection by wearable sensor and one-class SVM algorithm. In Proceedings of the Intelligent Computing in Signal Processing and Pattern Recognition, Kunming, China, 16-19 August 2006; Springer: Berlin/Heidelberg, Germany, 2006; Volume 345, pp. 858-863.

50. Lester, J.; Choudhury, T.; Kern, N.; Borriello, G.; Hannaford, B. A Hybrid Discriminative/Generative Approach for Modeling Human Activities; IJCAI, Professional Book Center: Edinburgh, Scotland, 2005; pp. 766-772.

51. Tong, L.; Song, Q.; Ge, Y.; Liu, M. HMM-based human fall detection and prediction method using tri-axial accelerometer. IEEE Sens. J. 2013, 13, 1849-1856. [CrossRef]

52. Florentino-Liano, B.; O’Mahony, N.; Artes-Rodrıguez, A. Hierarchical dynamic model for human daily activity recognition. In Proceedings of the Bio-Inspired Systems and Signal Processing (BIOSIGNALS), Vilamoura, Portugal, 1-4 February 2012; pp. 61-68.

53. Florentino-Liano, B.; O’Mahony, N.; Artes-Rodriguez, A. Human activity recognition using inertial sensors with invariance to sensor orientation. In Proceedings of the 3rd IEEE Workshop on Cognitive Information Processing (CIP), Baiona, Spain, 28-30 May 2012.

54. Yin, J.; Yang, Q.; Pan, J. Sensor-based abnormal human-activity detection. IEEE Trans. Knowledge Data Eng. 2008, 20, 1082-1090. [CrossRef]

55. Yu, M.; Naqvi, S.; Rhuma, A.; Chambers, J. One class boundary method classifiers for application in a video-based fall detection system. Comput. Vis. 2012, 6, 90-100. [CrossRef] 
56. Han, C.; Wu, K.; Wang, Y.; Ni, L. Wifall: Device-free fall detection by wireless networks. In Proceedings of the IEEE Transactions on Mobile Computing (INFOCOM), Toronto, ON, Canada, 27 April-2 May 2014; pp. 271-279.

57. Zhang, D.; Wang, H.; Wang, Y.; Ma, J. Anti-fall: A non-intrusive and real-time fall detector leveraging CSI from commodity WiFi devices. In Proceedings of the International Conference on Smart Homes and Health Telematics, Geneva, Switzerland, 10-12 June 2015; pp. 181-193.

58. Khan, M.; Yu, M.; Feng, P.; Wang, L.; Chambers, J. An unsupervised acoustic fall detection system using source separation for sound interference suppression. Signal Process. 2015, 110, 199-210. [CrossRef]

59. Parisi, G.I.; Wermter, S. Hierarchical SOM-based detection of novel behavior for 3D human tracking. In Proceedings of the International Joint Conference on Neural Networks (IJCNN), Dallas, TX, USA, 4-9 August 2013; pp. 1-8.

60. Noury, N.; Fleury, A.; Rumeau, P.; Bourke, A.K.; Laighin, G.O.; Rialle, V.; Lundy, J.E. Fall detection-Principles and methods. In Proceedings of the IEEE Engineering in Medicine and Biology Society, Lyon, France, 23-26 August 2007.

61. Auvinet, E.; Reveret, L.; St-Arnaud, A.; Rousseau, J.; Meunier, J. Fall detection using multiple cameras. In Proceedings of the Engineering in Medicine and Biology Society, Vancouver, BC, Canada, 20-25 August 2008.

62. Zigel, Y.; Litvak, D.; Gannot, I. A method for automatic fall detection of elderly people using floor vibrations and sound-Proof of concept on human mimicking doll falls. IEEE Trans. Biomed. Eng. 2009, 56, 2858-2867. [CrossRef] [PubMed]

63. Horton, K. Falls in older people: The place of telemonitoring in rehabilitation. Rehabil. Res. Dev. 2008, 45, 1183-1194. [CrossRef]

64. Brownsell, S.; Hawley, M. Fall detectors: Do they work or reduce the fear of falling? Hous. Care Support 2004, 7, 18-24. [CrossRef]

65. Kulkarni, A.U. Intelligent Pill Box. U.S. Patent 7,877,268, 25 January 2011.

66. De Oliveira, R.; Cherubini, M.; Nuria, O. MoviPill: Improving medication compliance for elders using a mobile persuasive social game. In Proceedings of the 12th ACM International Conference on Ubiquitous Computing, Copenhagen, Denmark, 26-29 September 2010.

67. MacLaughlin, E.J.; Raehl, C.L.; Treadway, A.K.; Sterling, T.L.; Zoller, D.P.; Bond, C.A. Assessing medication adherence in the elderly. Drugs Aging 2005, 22, 231-255. [CrossRef] [PubMed]

68. Moisan, J.; Gaudet, M.; Grégoire, J.-P.; Bouchard, R. Non-compliance with drug treatment and reading difficulties with regard to prescription labeling among seniors. Gerontology 2002, 48, 44-51. [CrossRef] [PubMed]

69. (SAMHSA) Substance Abuse and Mental Health Services Administration and Administration on Aging (AoA); Behavioral Health Technical Assistance Center: Rockville, MD, USA, 2012.

70. Yamamoto, Y.; Huang, R.; Ma, J. Medicine management and medicine taking assistance system for supporting elderly care at home. In Proceedings of the 2nd IEEE International Symposium on Aware Computing, Tainan, Taiwan, 1-4 November 2010.

71. Simoni-Wastila, L.; Yang, K. Psychoactive drug abuse in older adults. Am. J. Geriatr. Pharmacother. 2006, 4, 380-394. [CrossRef] [PubMed]

72. Center for Substance Abuse Treatment. Substance Abuse among Older Adults. Treatment Improvement Protocol; Substance Abuse and Mental Health Services Administration: Rockville, MD, USA, 1998.

73. National Institute on Alcohol Abuse and Alcoholism. Diagnostic Criteria for Alcohol Abuse; Alcohol Alert: Washington, DC, USA, 1995.

74. Cutler, M.; Everett, W. Thinking outside the pillbox-Medication adherence as a priority for health care reform. N. Engl. J. Med. 2010, 362, 1553-1555. [CrossRef] [PubMed]

75. Maddigan, L.; Farris, B.; Keating, N.; Wiens, A.; Johnson, A. Predictors of older adults' capacity for medication management in a self-medication program: A retrospective chart review. J. Aging Health 2003, 15, 332-352. [CrossRef] [PubMed]

76. Nikolaus, T.; Kruse, W.; Bach, M.; Specht-Leible, N.; Oster, P.; Schlierf, G. Elderly patients' problems with medication. An in-hospital and follow-up study. Eur. J. Clin. Pharmacol. 1996, 49, 255-259. [CrossRef] [PubMed] 
77. Mowerson, A. Helping patients with vision impairment adhere to a medication regime. J. Gerontol. Nurs. 2002, 28, 15-18. [CrossRef] [PubMed]

78. DiMatteo, R. Social support and patient adherence to medical treatment: A meta-analysis. Health Psychol. 2004, 23, 207-218. [CrossRef] [PubMed]

79. Agoulmine, N.; Deen, M.J.; Lee, J.S.; Meyyappan, M. U-health smart home. IEEE Nanotechnol. Mag. 2011, 5, 6-11. [CrossRef]

80. Yared, R.; Mallat, H.K.; Abdulrazak, B. Ambient Technology to Support Elderly People in Outdoor Risk Situations. In Information and Communication Technologies for Ageing Well and e-Health, Proceedings of the 1st International Conference on Information and Communication Technologies for Ageing Well and e-Health (ICT4AgeingWell), Lisbon, Portugal, 20-22 May 2015; Helfert, M., Holzinger, A., Ziefle, M., Fred, A., O’Donoghue, J., Röcker, C., Eds.; Communications in Computer and Information Science; Springer: Berlin/Heidelberg, Germany, 2015; Volume 578, pp. 35-36.

81. Mallat, H.K.; Yared, R.; Abdulrazak, B. Assistive Technology for Risks Affecting Elderly People in Outdoor Environment. In Proceedings of the 1st International Conference on Information and Communication Technologies for Ageing Well and e-Health (ICT4AgeingWell), Lisbon, Portugal, 20-22 May 2015; pp. 5-16.

82. Hayes, T.L.; Hunt, J.M.; Adami, A.; Kaye, J.A. An electronic pillbox for continuous monitoring of medication adherence. In Proceedings of the 28th Annual IEEE Conference on Engineering in Medicine and Biology Society, New York, NY, USA, 31 August-3 September 2006.

83. Sterns, A.; Hughes, J.; Masstandrea, N.; Smith, J. Medication Event Monitoring System. U.S. Patent 14,357,052, 12 November 2012.

84. Cramer, J.A.; Mattson, R.H.; Prevey, M.L.; Scheyer, R.D.; Ouellette, V.L. How often is medication taken as prescribed? A novel assessment technique. JAMA 1989, 261, 3273-3277. [CrossRef] [PubMed]

85. Keram, S.; Williams, M.E. Quantifying the ease or difficulty older persons experience in opening medication containers. J. Am. Geriatr. Soc. 1988, 36, 198-201. [CrossRef] [PubMed]

86. Atkin, P.A.; Finnegan, T.P.; Ogle, S.J.; Shenfield, G.M. Functional ability of patients to manage medication packaging: A survey of geriatric inpatients. Age Ageing 1994, 23, 113-116. [CrossRef] [PubMed]

87. Branin, J.J. The role of memory strategies in medication adherence among the elderly. Home Health Care Serv. Q. 2001, 20, 1-16. [CrossRef] [PubMed]

88. DiCarlo, L.A. Role for direct electronic verification of pharmaceutical ingestion in pharmaceutical development. Contemp. Clin. Trials 2012, 33, 593-600. [CrossRef] [PubMed]

89. Mobile Medication Therapy Management System Wins \$1M NIH Grant. Available online: http: //mobihealthnews.com/18496/mobile-medication-therapy-management-system-wins-1m-nih-grant/ (accessed on 8 October 2016).

90. Wan, D. Magic Medicine Cabinet: A situated portal for consumer healthcare. In Proceedings of the International Symposium on Handheld and Ubiquitous Computing HUC'99, Karlsruhe, Germany, 27-29 September 1999.

91. Fishkin, K.; Wang, M.; Borriello, G. A ubiquitous system for medication monitoring. In Proceedings of the Second International Conference on Pervasive Computing, Vienna, Austria, 21-23 April 2004.

92. Vinjumur, J.K.; Becker, E.; Ferdous, S.; Galatas, G.; Makedon, F. Web based medicine intake tracking application. In Proceedings of the 3rd ACM International Conference on Pervasive Technologies Related to Assistive Environments, Samos, Greece, 23-25 June 2010.

93. Marek, K.D.; Stetzer, F.; Ryan, P.A.; Bub, L.D.; Adams, S.J.; Schlidt, A.; Lancaster, R.; O’Brien, A.M. Nurse care coordination and technology effects on health status of frail elderly via enhanced self-management of medication: Randomized clinical trial to test efficacy. Nurs. Res. 2013, 62, 269-278. [CrossRef] [PubMed]

94. Sherrard, H.; Struthers, C.; Kearns, S.A.; Wells, G.; Chen, L.; Mesana, T. Using technology to create a medication safety net for cardiac surgery patients: A nurse-led randomized control trial. Can. J. Cardiovasc. Nurs. 2009, 19, 9-15. [PubMed]

95. Naditz, A. Medication compliance-Helping patients through technology: Modern "smart" pillboxes keep memory-short patients on their medical regimen. Telemed. J. e-Health 2008, 14, 875-880. [CrossRef] [PubMed]

96. Buckwalter, K.C.; Wakefield, B.J.; Hanna, B.; Lehmann, J. New technology for medication adherence: Electronically managed medication dispensing system. J. Gerontol. Nurs. 2004, 30, 5-8. [CrossRef] [PubMed]

97. Reminders, e-pill Medication e-pill Automatic Pill Dispensers 2011. Available online: http://www.epill. com/dispenser.html (accessed on 8 October 2016). 
98. Russell, C.L.; Conn, V.S.; Jantarakupt, P. Older adult medication compliance: Integrated review of randomized controlled trials. Am. J. Health Behav. 2006, 30, 635-650. [CrossRef]

99. Campbell, N.L.; Boustani, M.A.; Skopelja, E.N.; Gao, S.; Unverzagt, F.W.; Murray, M.D. Medication adherence in older adults with cognitive impairment: A systematic evidence-based review. Am. J. Geriatr. Pharmacother. 2012, 10, 165-177. [CrossRef] [PubMed]

100. Mehaffey, J.R.; Bert, J.L. Fire Protection Report; U.S. Department of Health and Human Services, National Institute for Occupational Safety and Health (NIOSH), Centers for Disease Control and Prevention: Washington, DC, USA, 1997.

101. Karter, M. National Fire Protection Association (NFPA)'s Latest Fire Loss Figures. NFPA J. 1996, 52-59.

102. Runyan, C.W.; Johnson, R.M.; Yang, J.; Waller, A.E.; Perkis, D.; Marshall, S.W.; McGee, K.S. Risk and protective factors for fires, burns, and carbon monoxide poisoning in US households. Am. J. Prev. Med. 2005, 28, 102-108. [CrossRef] [PubMed]

103. Ahrens, M. Home Smoke Alarms: The Data as Context for Decision. Fire Technol. 2008, 44, $313-327$. [CrossRef]

104. Office of the Fire Marshal. Reducing Stovetop Fire; Fire Marshal's Public: Brockville, ON, Canada, 2009.

105. Lushaka, B.; Zalok, E. Development of a sensing device to reduce the risk from kitchen fires. Fire Technol. J. 2014, 50, 791-803. [CrossRef]

106. Hall, J.R. Home Cooking Fire Patterns and Trends; National Fire Incident Reporting System (NFIRS): Quincy, MA, USA, 2006.

107. Abdulrazak, B.; Yared, R.; Tessier, T.; Mabilleau, P. Toward pervasive computing system to enhance safety of ageing people in smart kitchen. In Proceedings of the 1st International Conference of Information and Communication Technologies for Ageing Well and e-Health (ICT4AgeingWell2015), Lisbon, Portugal, 20-22 May 2015.

108. Yared, R.; Abdulrazak, B. Toward Context-Aware Smart Oven to Prevent Cooking Risks in Kitchen of Elderly People; Springer: Berlin/Heidelberg, Germany, 2015; pp. 57-77.

109. U.S. Fire Administration. Let's Retire Fire: A Factsheet for Older Americans; Department of Homeland Security: Emmitsburg, MD, USA, 2006.

110. Warda, L.; Tenenbein, M.; Moffatt, M.E. House fire injury prevention update. Part I. A review of risk factors for fatal and non-fatal house fire injury. Injury Prev. 1999, 5, 145-150. [CrossRef]

111. Grant, E.J. Preventing burns in the elderly: A guide for home healthcare professionals. Home Healthc. Nurse 2013, 31, 561-573. [CrossRef] [PubMed]

112. Stockhausen, A.L.; Katcher, M.L. Burn injury from products in the home: Prevention and counseling. Wis. Med. J. 2001, 100, 39-44.

113. American Academy of Pediatrics. Fires and burns. In Injury Prevention and Control for Children and Youth, 3rd ed.; Widome, M.D., Ed.; American Academy of Pediatrics, Committee on Injury and Poison Prevention: Elk Grove Village, IL, USA, 1997.

114. Burn Prevention Fact Sheet/Older Adult Educator's Guide; American Burn Association: Chicago, IL, USA, 2012.

115. Runyan, C.W.; Casteel, C.; Perkis, D. Unintentional injuries in the home in the United States. Part I: Mortality. Am. J. Prev. Med. 2005, 28, 73-79. [CrossRef] [PubMed]

116. Harwood, B. Common products that cause uncommonly severe burn injuries. NFPA J. 1995, 90, 79-83.

117. Macarthur, C. Evaluation of Safe Kids Week 2001: Prevention of scald and burn injuries in young children. Injury Prev. 2003, 9, 112-116. [CrossRef]

118. Rivara, F.P. Burns: The importance of prevention. Injury Prev. 2000, 6, 243-244. [CrossRef]

119. Stone, M.; Evans, A.J. The continuing risk of domestic hot water scalds to the elderly. Burns 2000, 26, 347-350. [CrossRef]

120. Weaver, A.M.; Himel, H.N.; Edlich, R.F. Immersion scald burns: Strategies for prevention. J. Emerg. Med. 1993, 11, 397-402. [CrossRef]

121. Shields, W.C.; Perry, E.C.; Szanton, S.L.; Andrews, M.R.; Stepnitz, R.L.; McDonald, E.M.; Gielen, A.C. Knowledge and injury prevention practices in homes of older adults. Geriatr. Nurs. 2013, 34, 19-24. [CrossRef] [PubMed]

122. Bishai, D.; Lee, S. Heightened risk of fire deaths among older African Americans and Native Americans. Public Health Rep. 2010, 125, 406-413. [PubMed] 
123. Ault, K.L. Estimates of Non-Fire Carbon Monoxide Poisoning Deaths and Injuries; U.S. Consumer Product Safety Commission: Washington, DC, USA, 1997.

124. Centers for Disease Control and Prevention. Use of unvented residential heating appliances-United States, 1988-1994. MMWR Morb. Mortal. Wkly. Rep. 1997, 46, 1221-1224.

125. Centers for Disease Control and Prevention. Unintentional carbon monoxide poisoning in residential settings-Connecticut, November 1993-March 1994. MMWR Morb. Mortal. Wkly. Rep. 1995, 44, 765-767.

126. Daley, W.R.; Smith, A.; Paz-Argandona, E.; Malilay, J.; McGeehin, M. An outbreak of carbon monoxide poisoning after a major ice storm in Maine. J. Emerg. Med. 2000, 18, 87-93. [CrossRef]

127. Girman, J.R.; Chang, Y.L.; Hayward, S.B.; Liu, K.S. Causes of unintentional deaths from carbon monoxide poisonings in California. West. J. Med. 1998, 168, 158-165. [PubMed]

128. Bizovi, K.E.; Leikin, J.B.; Hryhorczuk, D.O.; Frateschi, L.J. Night of the sirens: Analysis of carbon monoxide-detector experience in suburban Chicago. Ann. Emerg. Med. 1998, 31, 737-740. [CrossRef]

129. Meredith, T.; Vale, A. Carbon monoxide poisoning. Br. Med. J. 1988, 296, 77-79. [CrossRef]

130. Kelly, J.S.; Sophocleus, G.J. Retinal hemorrhages in subacute carbon monoxide poisoning. JAMA 1978, 239, 1515-1517. [CrossRef]

131. Stewart, R.D.; Hake, C.L. Paint-remover hazard. JAMA 1976, 235, 398-401. [CrossRef] [PubMed]

132. Stewart, R.D.; Baretta, E.D.; Platte, L.R.; Stewart, E.B.; Kalbfleisch, J.H.; Van Yserloo, B.; Rimm, A.A. Carboxyhemoglobin levels in American blood donors. JAMA 1974, 229, 1187-1195. [CrossRef] [PubMed]

133. Harvey, P.A.; Sacks, J.J.; Ryan, G.W.; Bender, P.F. Residential smoke alarms and fire escape plans. Public Health Rep. 1998, 113, 459-464. [PubMed]

134. Mayer, M.; LeClere, F.B. Injury prevention measures in households with children in the United States. Adv. Data 1994, 250, 1-16. [PubMed]

135. Centers for Disease Control and Prevention. Deaths resulting from residential fires and the prevalence of smoke alarms-United States, 1991-1995. MMWR Morb. Mortal. Wkly. Rep. 1998, 47, 803-806.

136. Doman, K.; Kuai, Y.; Takahashi, T.; Ide, I.; Murase, H. Video Cooking: Towards the Synthesis of Multimedia Cooking Recipes. In Advances in Multimedia Modeling, Proceedings of the 17th International Multimedia Modeling Conference, MMM 2011, Taipei, Taiwan, 5-7 January 2011; Lee, K.-T., Tsai, W.-H., Liao, H.-Y.M., Chen, T., Hsieh, J.-W., Tseng, C.-C., Eds.; Lecture Notes in Computer Science. Springer: Berlin/Heidelberg, Germany, 2011; Volume 6524, pp. 135-145.

137. Li, Y.; Asghar, Z.; Pulii, P. Visually-aided smart kitchen environment for senior citizens suffering from dementia. In Proceedings of the IEEE International Joint Conference on Awareness Science and Technology and Ubi-Media Computing (iCAST-UMEDIA), Aizuwakamatsu, Japan, 2-4 November 2013.

138. Sanchez, A.; Burnell, L. Intelligent and Adaptive Educational-Learning Systems. In Smart Innovation, Systems and Technologies; Springer: Berlin/Heidelberg, Germany, 2013; Volume 17, pp. 293-314.

139. Alwan, M.; Dalal, S.; Mack, D.; Kell, B.; Turner, J. Leachtenauer and Felder. Impact of monitoring technology in assisted living: Outcome pilot. IEEE Trans. Inf. Technol. Biomed. 2006, 10, 192-198. [CrossRef] [PubMed]

140. Wai, A.; Shanthini, D.; Biswas, J.; Panda, S. Pervasive intelligence system to enable safety and assistance in kitchen for home-alone elderly. In Toward Useful Services for Elderly and People with Disabilities; Springer: Berlin/Heidelberg, Germany, 2011; pp. 276-280.

141. Yuan, M.Y.; Green, J.R.; Goubran, R. Thermal imaging for assisted living at home: Improving kitchen safety. J. Med. Biol. Eng. 2012, 33, 380-387. [CrossRef]

142. Nagashima, T.; Mammoto, A.; Yamauchi, Y.; Watanabe, K.; Mizobuchi, M. Optimization of sensitivity characteristics of photoelectric smoke detector to various smokes. Fire Saf. Sci. 1988, 3, 319-334.

143. Chen, S.; Bao, H.; Zeng, X.; Yang, Y. A fire detecting method based on multi-sensor data fusion. In Proceedings of the IEEE International Conference on Systems, Man and Cybernetics, Washington, DC, USA, 5-8 October 2003; Volume 4, pp. 3775-3780.

144. Hagen, C.; Milke, A. The use of gaseous fire signatures as a mean to detect fires. Fire Saf. J. 2000, 34, 55-67. [CrossRef]

145. Johnson, E. Study of Technology for Detecting Pre-Ignition Conditions of Cooking-Related Fires Associated with Electric and Gas Ranges and Cooktops; Technical Report; US Department of Commerce, Technology Administration, National Institute of Standards and Technology: Gaithersburg, MD, USA, 1998.

146. Milke, A.; McAvoy, J. Analysis of signature patterns for discriminating fire detection with multiple sensors. Fire Technol. 1995, 31, 120-136. [CrossRef] 
147. Milke, A.; Hulcher, E.; Worrell, L.; Gottuk, T.; Williams, W. Investigation of Multi-Sensor algorithms for fire detection. Fire Technol. 2003, 39, 363-382. [CrossRef]

148. Bashyal, S.; Venayagamoorthy, G.; Paudel, B. Embedded neural network for fire classification using an array of gas sensors. In Proceedings of the IEEE Symposium on Sensors Applications, Daegu, Korea, 12-14 February 2008.

149. Charumporn, B.; Yoshioka, M.; Fujinaka, T.; Omatu, S. Early stage fire detection using reliable metal oxide gas sensors and artificial neural networks. In Proceedings of the International Joint Conference on Neural Networks, Portland, OR, USA, 20-24 July 2003; pp. 3185-3188.

150. Yared, R.; Abdulrazak, B.; Tessier, T.; Mabilleau, P. Cooking risk analysis to enhance safety of elderly people in smart kitchen. In Proceedings of the 8th ACM International Conference on Pervasive Technologies Related to Assistive Environments (PETRA'2015), Corfu, Greece, 1-3 July 2015.

151. Abdulrazak, B.; Yared, R. Prevent Cooking Risks in Kitchen of Elderly People: Adaptable Reasoning Engine Based on Fuzzy Logic for Smart Oven. In Proceedings of the IEEE International Conference on Computer and Information Technology; Ubiquitous Computing and Communications; Dependable, Autonomic and Secure Computing; Pervasive Intelligence and Computing (CIT/IUCC/DASC/PICOM), Liverpool, UK, 26-28 October 2015; pp. 2165-2172.

152. Virtual Flame. Available online: http://www.samsung.com/uk/consumer/home-appliances/cookingappliances/induction/NZ63J9770EK/EU (accessed on 8 October 2016).

153. Carbon Monoxide Detectors Can Save Lives; U.S. Consumer Product Safety Commission: Washington, DC, USA, 2003.

154. Yoon, S.S.; Macdonald, S.C.; Parrish, R.G. Deaths from unintentional carbon monoxide poisoning and potential for prevention with carbon monoxide detectors. JAMA 1998, 279, 685-687. [CrossRef] [PubMed]

155. Clifton, J.C.; Leikin, J.B.; Hryhorczuk, D.O.; Krenzelok, E.P. Surveillance for carbon monoxide poisoning using a national media clipping service. Am. J. Emerg. Med. 2001, 19, 106-108. [CrossRef] [PubMed]

156. Krenzelok, E.P.; Roth, R.; Full, R. Carbon monoxide ... the silent killer with an audible solution. Am. J. Emerg. Med. 1996, 14, 484-486. [CrossRef]

157. Centers for Disease Control and Prevention. Use of carbon monoxide alarms of prevent poisonings during a power outage-North Carolina, December 2002. MMWR Morb. Mortal. Wkly. Rep. 2004, 53, 189-192.

158. Jain, P.C.; Kushwaha, R. Wireless gas sensor network for detection and monitoring of harmful gases in utility areas and industries. In Proceedings of the IEEE Sixth International Conference on Sensing Technology (ICST), West Bangal, India, 18-21 December 2012.

159. Harper, A.; Croft-Baker, J. Carbon monoxide poisoning: Undetected by both patients and their doctors. Age Ageing 2004, 33, 105-109. [CrossRef] [PubMed]

160. Helal, A.; Mokhtari, M.; Abdulrazak, B. The Engineering Handbook of Smart Technology for Aging, Disability, and Independence; Wiley: Hoboken, NJ, USA, 2008.

161. Alspach, J.G. Loneliness and social isolation: Risk factors long overdue for surveillance. Crit. Care Nurse 2013, 33, 8-13. [CrossRef] [PubMed]

162. Wang, H.X.; Karp, A.; Winblad, B.; Fratiglioni, L. Late-life engagement in social and leisure activities is associated with a decreased risk of dementia: A longitudinal study from the Kungsholmen project. Am. J. Epidemiol. 2002, 155, 1081-1087. [CrossRef] [PubMed]

163. Morrow-Howell, N.; Putnam, M.; Lee, Y.S.; Greenfield, J.C.; Inoue, M.; Chen, H. An investigation of activity profiles of older adults. J. Gerontol. Ser. B Psychol. Sci. Soc. Sci. 2014. [CrossRef] [PubMed]

164. Phillips, E.M.; Schneider, J.C.; Mercer, G.R. Motivating elders to initiate and maintain exercise. Arch. Phys. Med. Rehabil. 2004, 85 (Suppl. 3), 52-57. [CrossRef]

165. Krueger, K.R.; Wilson, R.S.; Kamenetsky, J.M.; Barnes, L.L.; Bienias, J.L.; Bennett, D.A. Social engagement and cognitive function in old age. Exp. Aging Res. 2009, 35, 45-60. [CrossRef] [PubMed]

166. Unger, J.B.; McAvay, G.; Bruce, M.L.; Berkman, L.; Seeman, T. Variation in the Impact of Social Network Characteristics on Physical Functioning in Elderly Persons: MacArthur Studies of Successful Aging. J. Gerontol. Ser. B Psychol. Sci. Soc. Sci. 1999, 54, S245-S251. [CrossRef]

167. Araullo, J.; Potter, L.E. Promoting physical activity in seniors: Future opportunities with emerging technologies. In Proceedings of the 2016 ACM SIGMIS Conference on Computers and People Research, Washington, DC, USA, 2-4 June 2016; pp. 57-64. 
168. Lee, I.M.; Shiroma, E.J.; Lobelo, F.; Puska, P.; Blair, S.N.; Katzmarzyk, P.T.; Lancet Physical Activity Series Working Group. Effect of physical inactivity on major non-communicable diseases worldwide: An analysis of burden of disease and life expectancy. Lancet 2012, 380, 219-229. [CrossRef]

169. Buttussi, F.; Chittaro, L. Smarter phones for healthier lifestyles: An adaptive fitness game. IEEE Pervasive Comput. 2010, 9, 51-57. [CrossRef]

170. Madeira, R.N.; Costa, L.; Postolache, O. PhysioMate-Pervasive physical rehabilitation based on NUI and gamification. In Proceedings of the IEEE International Conference on Electrical and Power Engineering (EPE), Iasi, Romania, 16-18 October 2014; pp. 612-616.

171. Barua, D.; Kay, J.; Paris, C. Viewing and controlling personal sensor data: What do users want? In Proceedings of the International Conference on Persuasive Technology, Sydney, Australia, 3-5 April 2013; Springer: Berlin/Heidelberg, Germany, 2013; pp. 15-26.

172. Mitchell, L.; Ziviani, J.; Oftedal, S.; Boyd, R. The effect of virtual reality interventions on physical activity in children and adolescents with early brain injuries including cerebral palsy. Dev. Med. Child Neurol. 2012, 54, 667-671. [CrossRef] [PubMed]

173. Bice, M.R.; Ball, J.W.; McClaran, S. Technology and physical activity motivation. Int. J. Sport Exerc. Psychol. 2015, 1-10. [CrossRef]

174. Consolvo, S.; Everitt, K.; Smith, I.; Landay, J.A. Design requirements for technologies that encourage physical activity. In Proceedings of the SIGCHI Conference on Human Factors in Computing Systems, Montreal, QC, Canada, 24-27 April 2006; Volume 1, pp. 457-466.

175. Stanley, K.G.; Livingston, I.; Bandurka, A.; Kapiszka, R.; Mandryk, R.L. "PiNiZoRo": A GPS-based exercise game for families. In Proceedings of the International Academic Conference on the Future of Game Design and Technology (FuturePlay'10), Vancouver, BC, Canada, 6-7 May 2010; pp. 243-246.

176. Brox, E.; Hernandez, J.E.G. Exergames for elderly: Social exergames to persuade seniors to increase physical activity. In Proceedings of the 5th IEEE International Conference on Pervasive Computing Technology for Healthcare, Dublin, Ireland, 23-26 May 2011; pp. 546-549.

177. Albaina, I.M.; Visser, T.; van der Mast, C.A.P.G.; Vastenburg, M.H. Flowie: A persuasive virtual coach to motivate elderly individuals to walk. In Proceedings of the International ICST Conference on Pervasive Computing Technologies for Healthcare, London, UK, 1-3 April 2009; pp. 1-7.

178. Ponce, V.; Deschamps, J.P.; Giroux, L.P.; Salehi, F.; Abdulrazak, B. QueFaire: Context-aware in-person social activity recommendation system for active aging. In Proceedings of the International Conference on Smart Homes and Health Telematics, Geneva, Switzerland, 10-12 June 2015; pp. 64-75.

179. Romero, N.; Sturm, J.; Bekker, T.; de Valk, L.; Kruitwagen, S. Playful persuasion to support older adults' social and physical activities. Interact. Comput. 2010, 22, 485-495. [CrossRef]

180. Pasikowska, A.; Zaraki, A.; Lazzeri, N. A dialogue with a virtual imaginary interlocutor as a form of a psychological support for well-being. In Proceedings of the ACM International Conference on Multimedia, Interaction, Design and Innovation, Warsaw, Poland, 24-25 June 2013.

181. Bentley, F.R.; Basapur, S.; Chowdhury, S.K. Promoting intergenerational communication through location-based asynchronous video communication. In Proceedings of the 13th ACM International Conference on Ubiquitous Computing, Beijing, China, 17-21 September 2011; pp. 31-40.

182. MELCO project. Available online: www.melco.cs.ucy.ac.cy (accessed on 8 October 2016).

183. Co-Living project. Available online: http://project-coliving.eu (accessed on 8 October 2016).

184. Kaplan, A.M.; Haenlein, M. Users of the world, unite! The challenges and opportunities of social media. Bus. Horiz. 2010, 53, 59-68. [CrossRef]

185. Buettner, D. The Blue Zones: Lessons for Living Longer from the People Who've Lived the Longest; National Geographic Society: Washington, DC, USA, 2009.

186. Cohen-Mansfield, J.; Biddison, J. The scope and future trends of gerontechnology: Consumers' opinions and literature survey. J. Technol. Hum. Serv. 2007, 25, 1-19. [CrossRef]

187. Bolton, M. Older People, Technology and Community: The Potential of Technology to Help Older People Renew or Develop Social Contacts and to Actively Engage in Their Communities; Independent Age: London, UK, 2010.

188. Vichitvanichphong, S.; Talaei-Khoei, A.; Kerr, D.; Ghapanchi, A.H. Assistive technologies for aged care: Supportive or empowering? Australas. J. Inf. Syst. 2014, 18. [CrossRef] 
189. Olphert, W.; Damodaran, L.; Balatsoukas, P.; Parkinson, C. Process requirements for building sustainable digital assistive technology for older people. J. Assis. Technol. 2009, 3, 4-13. [CrossRef]

190. Nikou, S. Mobile technology and forgotten consumers: The young-elderly. Int. J. Consum. Stud. 2015, 39, 294-304. [CrossRef]

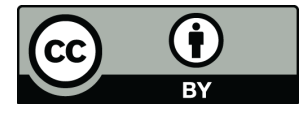

(c) 2016 by the authors; licensee MDPI, Basel, Switzerland. This article is an open access article distributed under the terms and conditions of the Creative Commons Attribution (CC-BY) license (http:/ / creativecommons.org/licenses/by/4.0/). 